\title{
Replicator dynamics in value chains: Explaining some puzzles of market selection
}

by Uwe Cantner, Ivan Savin, Simone Vannuccini

No. 83 | FEBRUARY 2016

\section{WORKING PAPER SERIES IN ECONOMICS}

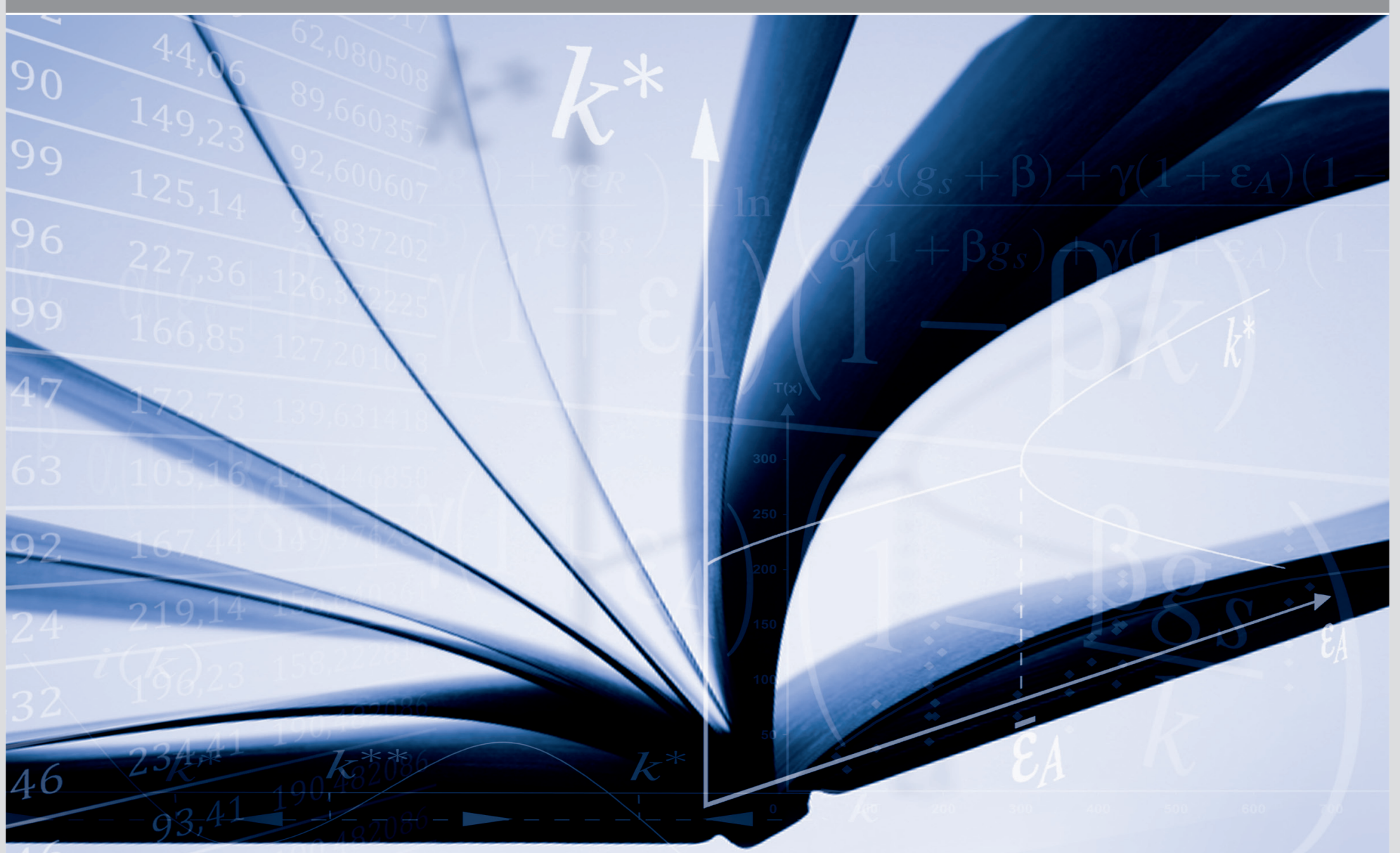




\section{Impressum}

Karlsruher Institut für Technologie (KIT)

Fakultät für Wirtschaftswissenschaften

Institut für Volkswirtschaftslehre (ECON)

Schlossbezirk 12

76131 Karlsruhe

KIT - Die Forschungsuniversität in der Helmholtz-Gemeinschaft

Working Paper Series in Economics

No. 83, February 2016

ISSN 2190-9806

econpapers.wiwi.kit.edu 


\title{
Replicator dynamics in value chains: explaining some puzzles of market selection*
}

\author{
U. Cantner, ${ }^{\dagger \ddagger}$ I. Savin ${ }^{\dagger \S}$ and S. Vannuccini ${ }^{\dagger}$
}

\begin{abstract}
The pure model of replicator dynamics though providing important insights in the evolution of markets has not found much of empirical support. This paper extends the model to the case of firms vertically integrated in value chains. We show that i) by taking value chains into account, the replicator dynamics may revert its effect. In these regressive developments of market selection, firms with low fitness expand because of being integrated with highly fit partners, and the other way around; ii) allowing partner's switching within a value chain illustrates that periods of instability in the early stage of industry life-cycle may be the result of an 'optimization' of partners within a value chain providing a novel and simple explanation to the evidence discussed by Mazzucato (1998); iii) there are distinct differences in the contribution to market selection between the layers of a value chain, causing strategic advantages to firms in partnering.
\end{abstract}

Keywords: innovation, replicator dynamics, returns to scale, value chain.

JEL Classification: C63, D24, L14, O32.

*All authors acknowledge financial support from the German Science Foundation (DFG RTG 1411). IS also acknowledges support from the Helmholtz Association (HIRG-0069) and Projex CSES, Initiative d'Excellence, Université de Strasbourg. The usual disclaimers apply. This paper is also circulating in the working paper series of BETA (http://www.beta-umr7522.fr/productions/workingpapers.php) and FSU Jena (http://zs.thulb.uni-jena.de/receive/jportal_jpjournal_00000016)

${ }^{\dagger}$ Faculty of Economics and Business Administration, Friedrich Schiller University of Jena, Germany

${ }^{\ddagger}$ Department of Marketing and Management, University of Southern Denmark, Denmark

${ }^{\S}$ Chair for Economic Policy, Karlsruhe Institute of Technology, Germany and Bureau d'Economie Théorique et Appliquée, UMR 7522 Université de Strasbourg - CNRS, France

ฯ Corresponding author: Kaiserstrasse 12 Geb. 20.14 Room 204, D-76131 Karlsruhe, Germany. Tel.: +49-721-60845754, Fax: +49-721-60845255, Ivan.Savin@kit.edu 


\section{Introduction}

This paper studies the role of firms integration into value chains (hereinafter VC) on competitive market selection. Under the integration into value chains we mean that the performance of a firm is not only dependent on its own performance (e.g., productivity, profitability) but also on that of its partners with whom it is vertically related to produce a finished good for consumers.17 Within a value chain, trust and division of labor among supplier and user industries is enhanced, while flexibility in the choice of partners is lower compared to a pure arm-length market transaction, where firm can compete for the best suppliers. The idea that accounting for value chain relations may shed some light on competition dynamics extends and may be at odds with the original stylized model of market selection developed by Metcalfe (1994) (also known as 'replicator dynamics model') $\left.\right|^{2}$

In the classic replicator dynamics model, vertical relationships among firms can be implicitly considered only as long as their effect is homogeneous across the firms acting in the focal market. The differential performance of firms is therefore only attributable to different idiosyncratic competences and abilities. Contrariwise, we argue that this connection can have a decisive influence on firms' success or failure in market selection, given that value chains can be highly heterogeneous due to suppliers' different costs structures and product qualities, and to a certain degree of stickiness of the connections. The importance of firms' vertical relations is confirmed not only by marketing research reporting that the value of business-to-business (B2B) contracts in many industries is exceeding the one from the business-to-consumer (B2C) $]^{3}$ but also by numerous studies pointing to the fact that in the modern economy the degree of specialization and division of labor is constantly increasing and instead of conducting the entire production cycle in-house, many stages get outsourced to firms specializing in certain tasks and phases of the production process, due to their higher productivity or possess of specific resources and capabilities. An important feature of that vertical relationships, however, is that firms collaborating on a long term basis adjust their production process to each other so that switching one's partner becomes a very (if not prohibitively) costly issue. As a result, over time a firm may get locked into cooperation with less fit partners, which has a direct impact on the firm's performance and market share development.

The principle of reallocation of market shares from less efficient firms to their more fit competitors is the key principle of selection-based theories (Friedman, 1953 ; Foster et al. 2008), which also play an important role in the evolutionary economics literature (Nelson and Winter, 1982). However, when it comes to empirical testing of the theory, evidence of that principle is at best mixed and at worst contradictory (Cantner, 2014). A first set of explanations for this set of results ranges from the choice of not appropriate variables for firm performance (fitness) to not clearly demarcated units and populations under

\footnotetext{
${ }^{1}$ In the paper, we use the term fitness rather then performance to indicate the abstract 'goodness' of the unit of analysis with respect to its reference group (competitors) or environment (industry, market) to keep consistency with the literature on the replicator dynamics.

${ }^{2}$ An alternative derivation of the replicator dynamics used by economics scholars can be found in Schuster and Sigmund (1983). See Silverberg (1997) for a discussion.

${ }^{3}$ The major reason for this is that in a typical supply value chain there are many B2B transactions involving sub-components or raw materials, and only one $\mathrm{B} 2 \mathrm{C}$ transaction, namely sale of the finished good to the end customer. For example, a computer manufacturer makes several B2B transactions such as buying microchips, different cables, cooler, which producers in their turn buy, e.g., nanometer transistors, rubber, plastic and metal.
} 
analysis (firms vs products, industries vs markets/sub-markets). Other explanations refer to neglected fitness relevant components (such as sunk costs, see Hölzl, 2015) or — as in this paper - to the exclusion of factors relevant for market share changes such as a firm's integration into a value chain. The topic of vertical relations and value chains is usually studied through the lenses of transaction-cost theories, in order to assess advantages and disadvantages of integration and complex contractual arrangements (Bresnahan and Levin, 2012). By linking the literature on vertical relations and market selection, this paper fills a relevant gap and is the first, to our knowledge, to explicitly model vertical relations as determinants of selection dynamics.

Dealing with the market performance of firms integrated in the value chain requires to take into account how the market performance of the downstream firm influences the market performance of the upstream firm and vice-versa. To simplify the issue at stake, in this study we assume that the number of output units of the downstream firm entirely determines the number of output units of the upstream firm. This strict relation implies that capacity expansion (or reduction) of the upstream firm is not only dependent on this firm success in its own market but also on the success of the downstream firm in her market. At the limit, such an assumption implies that the replicator dynamics is factually at work only in the final good market, while upstream firms just respond to downstream market shares reallocation. This simplification becomes useful when we assess through decomposition methods the effects on selection due to downstream competition and innovation dynamics in all the layers of the value chain. By applying simulation techniques we are interested under which constellation of value chain relationships the usually expected outcome of the replicator dynamics is not showing up or even reversed in its results.

The paper proceeds as follows. The next section provides a literature review together with hypotheses to be tested. Section 3 describes the model of the replicator dynamics into the value chain context while in Section 4 its main results are summarized. Section 5 discusses the model's implications and concludes.

\section{Literature Review and Hypotheses}

In what follows we review the literature whose main focus is the empirical study of market selection and market shares reallocation. In a nutshell, the theoretical prediction of the replicator dynamics goes in line with the Darwinian 'survival of the fittest' principle: ideally, a firm with a higher (lower) fitness than the (share-weighted) average of the population increases (decreases) its market share and drives further the selection dynamics by affecting the level of the share-weighted average fitness in the following periods, unless negative feedbacks dampen the dynamics.

Empirically, the literature on market shares reallocation and selection is strongly related to that on productivity dynamics, especially at the micro level. The latter has been boosted by the recent availability of firm and establishment level data, which start to shed some light on the determinants of firm's heterogeneity and characteristics (e.g. productivity and profitability) dispersion (Bartelsman, 2010). As a first approximation, we can distinguish between studies grounded on Empirical Industrial Organization (EIO) on the one hand and Neo-Schumpeterian theories on the other hand; however, the papers classified in this rough taxonomy often share a consistent part of methodological premises.

The first strand of research - that studying market selection from an EIO perspective

— descends from models of industry 'equilibrium evolution' (such as Jovanovic, 1982 and 
Hopenhayn, 1992) and operates a 'dissection' of aggregate productivity (usually at the industry level) by decomposing it in more fundamental components, either in a static or dynamic way. Static decompositions follow from the seminal exercise of Olley and Pakes (1996), that separates the first moment of the productivity distribution (the non-weighted average productivity) from a covariance term, measuring the distortion provoked by the reallocation of shares from less to more productive firms. Maliranta and Määttänen (2015) extend the static Olley-Pakes decomposition to account for different categories of firms (stayers, entrants, exiters and visitors). Dynamic decompositions usually build upon the contribution of Baily and Campbell (1992) to explain changes in aggregate productivity, rather than its level. Griliches and Regev (1995) and Foster et al. (2001) extend the dynamic decomposition framework to account for entry and exit (the two methods differ only with respect to the benchmark productivity used to calculate the change). Dynamic decompositions distinguish between two main sources of productivity change: a within component, usually interpreted in terms of firm-specific learning, and a between (plus covariance) component, capturing the competition and reallocation (selection) dynamics. A combination of the static and dynamic decomposition is derived in Melitz and Polanec (2015), where a dynamic Olley-Pakes decomposition with entry and exit is considered in order to explain aggregate productivity changes while maintaining the distributional approach of the static methods. From the theoretical side, Foster et al. (2008) discuss the nature of selection on productivity and profitability by building and estimating a model in which the selection dynamics is determined by 'physical' productivity, prices, and demand shocks. In general, the assessment of market selection in the literature described above is what we label an 'indirect' one, since the replicator dynamics is not tested explicitly but inferred through the sign and magnitude of the between effect.

The Neo-Schumpeterian literature addresses as well the issues of productivity dispersion, firms heterogeneity and the interaction between learning and selection. However, these studies rely more explicitly on the evolutionary assumptions of the replicator dynamics model; the idea is to test Schumpeter's concept of competition for the market, rather than competition in the market. Again using indirect methods (namely the Foster et al., 2001 decomposition), Cantner and Krüger (2008) and Krüger (2014) find for German manufacturing firms over the period 1981-1998 a weak tendency that above-average productivity firms are selected in favor of below-average productivity firms - this supporting a market selection process in line with the replicator dynamics. By splitting the sample in two periods (before and after German reunification), Cantner and Krüger (2008) are able to highlight the stronger effect of market reallocation in the period 19901998 , interpreted as a consequences of increased competition due to the reunification shock. In a follow-up study by Krüger (2014), however, these results could not be confirmed. Similar results have been also obtained by Bottazzi et al. (2008) and Coad (2007), where it is the within component - that is, learning - that mainly drives productivity growth. In general, Metcalfe and Ramlogan (2006) take a critical view to the decomposition exercises, considering them on the one hand useful to uncover the dynamics behind the restless nature of capitalism, but on the other hand sensible to the assumptions on the 'shapes' of the within and between components. They call for a sound theory of the interplay between innovation and market reallocation, to be constructed above these 'evolutionary accounting' methods.

Beyond the indirect approaches, some studies attempted a direct operationalisation of the replicator dynamics. In particular, Metcalfe and Calderini (2000) measured the speed of selection, a specific parameter in the replicator equation, for a dataset of the Italian 
steel industry. They cannot convincingly show that an evolutionary process according to replicator dynamics is at work. More recently, Dosi et al. (2015) have enriched the picture on the strength of selection combining direct and indirect approaches. In their analysis they conduct a decomposition exercise using firm level productivity data for four countries (US, France, Germany and the UK), and also estimate directly the speed of selection for different industries in each country. For both exercises, the results are rather mixed, not supporting the standard replicator model. A major reason is that an industry is not a market but a collection of markets, the firms are multi-product, and the fitness variable is entirely supply-side determined, in particular, in terms of unit costs of production. Cantner et al. (2012) take up this criticism and analyze the rather narrowly defined market for compact cars in Germany using a relative quality-price ratio, obtained aggregating information over four main product characteristics and prices, as proxy for a firm fitness. They find rather compelling evidence for the selection effect working in the expected direction.

Now, the replicator dynamics suggests that a firm's market share change is positively related to that firms relative performance in production; hence a firm that compared to the other firms shows an above (below) average production performance is expected to increase (decrease) her market share. That mechanism at work requires a market with one price (and market clearing) and profits (or losses) being used to invest into capacity expansion (or for disinvestment, respectively). Market shares have to develop accordingly. With a firm's integration into value chains this mechanism may not work properly. A first issue is the law of one price: With long-term relationships special prices can be negotiated, leading to heterogeneity in prices. A second issue, related to the former, is that vertically related firms may cooperate and hence investment is done together. A third issue is related to the demand for an intermediate product: if the downstream firm performs successfully, it will increase its productive capacity and by this increase the demand for the intermediate product; hence, the intermediate supplier, even when performing below average in its own market, will face this increased demand, provide the necessary expansion in capacity and experience a growing market share. All these constellations are at odds with the ideal selection mechanism and may lead to the observation that in a specific market a below average performing firm is able to increase market shares because her very well performing partners along the value chain are able and willing to pay higher intermediate product prices or are engaged in an investment cooperation with that firm or demand more intermediate products.

In the following model we just argue in terms of the output relationships between firms along a value chain and leave aside the features of differentiated prices and cooperation in investment. To analyze this framework, we suggest the following hypotheses:

1. In case all firms of a value chain hold in their own market the same production performance position, then market selection in each market should follow the principle of replicator dynamics.

2. In case of downstream firms in their own market show a higher rank in terms of production performance than their partners in upstream markets, the principle of replicator dynamics does not necessarily hold in upstream markets. 


\section{Basic Model}

We start by clarifying the variables and notation we use in this study. This first means to determine which is the chosen proxy for the fitness variable. As it is clear from the literature review, any performance indicator may serve the scope; usually more or less elaborated versions of the (labor or total factor) productivity, product quality or costs are used. In order to ease the comparison and to highlight our contribution with respect to other modeling exercises (e.g. Mazzucato, 1998), we first define firm's total unit cost $C_{m}^{i}$ (for each firm $i$ on value chain layer $m$ ). Being the result of a successive transfer of intermediate goods from layer to layer, the unit price of layer $m-1$ becomes part of the total unit cost of layer $m$, to which its own layer-specific unit cost has to be added. In general, the total unit cost for each layer can be decomposed as $C_{m}^{i}=p_{m-1}^{i}+c_{m}^{i}$, where $p_{m-1}^{i}$ is the price of the intermediate good of the upstream layer $m-1$ and $c_{m}^{i}$ is the layer-specific unit cost. The price of the upstream intermediate good $m-1$ can be expressed as $p_{m-1}^{i}=p_{m-2}^{i}+c_{m-1}^{i}(1+\phi)$, where $\phi$ is a constant markup, calculated on the 'value added' rather than on the cost of all supplies. Hence, for any value chain, for the first layer (layer one) $C^{i}$ and $c^{i}$ are assumed to be identical $\left(C_{1}^{i}=c_{1}^{i}\right)$, as the firm has only its own cost of extracting primary resources of production; for the second layer of the value chain, the total unit cost becomes $C_{2}^{j}=c_{2}^{j}+p_{1}^{j}=c_{2}^{j}+c_{1}^{j}(1+\phi)$ and so on until for the $M$ th layer of production, $C_{M}^{j}=c_{M}^{j}+p_{M-1}^{j}=c_{M}^{j}+\sum_{m=1}^{M-1} c_{m}^{j}(1+\phi)$.

Last layer total unit cost $C_{M}^{i}$, that equals the whole value chain unit cost, is our fitness variable (equations (5.1) to (5.4) in what follows explain why we use only $C_{M}^{i}$ as fitness, assuming that shares dynamics in all the upstream markets follow the behavior of the last - downstream - market). We sometimes also refer to this variable as aggregate fitness. Hereinafter, whenever not differently specified, the use of the term total unit cost refers to $C_{M}^{i}$, the last layer (and the whole value chain) cost.

\section{Further assumptions:}

1. there are $M$ (let us start for simplicity with three) vertically integrated markets, where on each market $N_{m}$ firms are operating. One can refer to those three layers as 'suppliers', 'manufacturers' and 'distributors';

2. no firm can produce a finished good alone, but only in cooperation with firms in other markets. Thus, we leave out the possibility of vertical integration with one single firm present on more than one layer (market);

3. we abstract from entry and exit behavior to isolate the effect of selection dynamics $\left(\forall m=1, \ldots, M N_{m}=\right.$ constant $) ;$

4. for the sake of simplicity, we also ignore sources of uncertainty for value chains such as demand (volume and product specification), process (e.g., machine downtime and transportation reliability) and supply (e.g., delivery reliability) described in detail in Strader et al. (1998). Instead, we assume perfect collection and sharing of information between supply chain members, which results in no inventories necessary and order fulfillment cycle time being minimized. Such a perfect management of lead-time in turn presents a barrier for value chain members to switch their partners, since tuning of this management is costly in terms of time and resources. In absence of any friction or asymmetry, this assumption may create the conditions for the establishment of vertically-integrated firms. However, this possibility is ruled 
out by assumption two: the impossibility of integration may be anyway justified with arguments related to product complexity, specialization and division of labor.

5. also for simplicity, goods on each market (including the market of finished good $M$ ) are homogeneous: market dynamics is only driven by firms' differential fitness;

6. firms on all $M$ layers seek to earn profit. Thus, on all $M$ layers profit margin per unit of output firms charge is fixed (parameter $\phi=0.1=\frac{p_{m}^{i}-c_{m}^{i}}{c_{m}^{i}}(10 \%)$ ), where $p$ indicates the price and $c_{m}^{i}$ the firm and layer specific cost. In principle, one could abandon that parameter. However, since firms in our model implicitly conduct costreducing $\mathrm{R} \& \mathrm{D}$, we consider positive profits in order to add realism to the model. One can later investigate the role played by different markup settings;

7. another standard assumption from replicator model adopted in this study is the investment in capacity extension: whenever a firm makes profits by selling its output at a price above its costs, a portion of the profit is invested in increasing its capacity $g_{m}^{i}=\lambda\left(p_{m}^{i}-c_{m}^{i}\right)=\frac{y_{m}^{i, t}-y_{m}^{i, t-1}}{y_{m}^{i}}$, where $g$ is the firm growth rate, which in turn is defined as the ratio of its output $y$ rate of change over its total production. $\lambda$ indicates the (constant) share of investment out of unit profits; unless specified differently, we set the parameter $\lambda=0.01$.

From the replicator model (Metcalfe, 1994) we know that market share $s_{m}^{i}=\frac{y_{m}^{i}}{y_{m}}$ of firm $i$ on market $m$ changes according to the following selection equation, where the term $f$ stands for 'fitness':

$$
\Delta s^{i, t}=s^{i, t}-s^{i, t-1}=s^{i, t} \lambda\left(f^{i, t-1}-\bar{f}^{t-1}\right) .
$$

As anticipated in the introduction, given that we consider a naive value chain structure with only one connection in each layer and no other markets (or firms) connected to those considered here, one can reasonably argue that the unit output of firm $j$ in the final layer must be equal to its supplier's one in each preceding layer $y_{M}^{i}=y_{M-1}^{i}=\ldots=y_{1}^{i}$, while the total unit output of market $M$ is equal to the preceding ones: $y_{M}=y_{M-1}=\ldots=y_{1}$. As a consequence, the following equalities must hold:

$$
\Delta y_{M}=\Delta y_{M-1}=\cdots=\Delta y_{1}
$$

i.e. aggregate changes in outputs on all markets are equal.

$$
\Delta y_{M}^{j}=\Delta y_{M-1}^{j}=\cdots=\Delta y_{1}^{j} .
$$

i.e. changes in outputs of all firms on different layers matched into one value chain are also equal. As a result, on can state that also changes in market share of all firms from different layers related to one value chain are also the same:

$$
\Delta s_{M}^{j}=\Delta s_{M-1}^{j}=\cdots=\Delta s_{1}^{j} .
$$




\section{Results}

In the following we explore the behavior of the model under different scenarios summarizing our results in five propositions.

\subsection{Random Value Chain Matching With No Innovation}

We consider two contrasting scenarios: in the first one, firms located on each market $m$ have their layer-specific unit cost drawn in a way that each downstream firm surpasses the next one by the same amount (e.g., 1, 1.5, 2,...); the firms integrated in a value chain are matched according to their fitness: the most fit firm in market $M$ with the most fit ones in market $M-1, M-2$ etc. and the other way around. In the second scenario, firms having their fitness drawn the same way as in the first scenario are matched randomly - some less fit firms may be matched with more fit ones (see Figure 11). To focus on the selection dynamics driven by VC relations, we assign to all the firms the same initial market share.
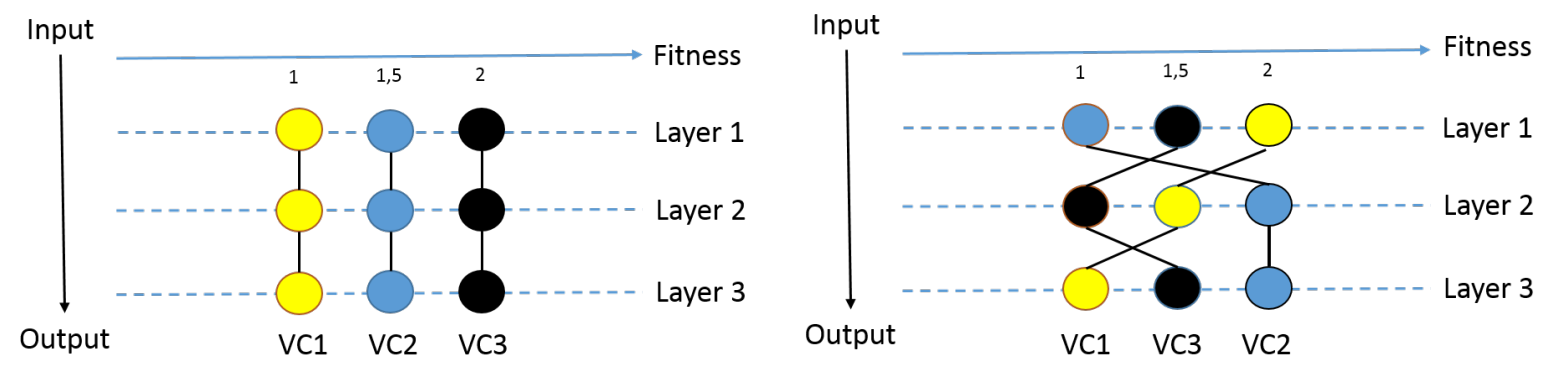

Figure 1: Firms' ordered and random matching in value chains

Note: The left panel corresponds to ordered matching, while the right one to random matching.

Let us denote the most fit firm in each layer with index $a$, the second most fit with $b$ and (for the simplified case of three firms only) the least fit firm with $c$. Hence, in the ordered matching we have all $a$ firms linked together (having total unit cost $C_{M}^{a}$ ), while in the random matching - they are randomly distributed in different VCs. Therefore, in the ordered matching scenario (benchmark) the most fit firm in each layer increases its market share according to equation (1). In particular,

$$
\Delta s_{M}^{a, t}=s^{a, t}-s^{a, t-1}=s_{M}^{a, t} \lambda\left(\bar{C}_{M}^{t-1}-C_{M}^{a, t-1}\right) .
$$

The difference between (5) and (1) is that the 'monopolization' takes place for the VC case even faster since

$$
\begin{aligned}
C_{M}^{a}-C_{M}^{b} & =c_{M}^{a}+\sum_{m=1}^{M-1} c_{m}^{a}(1+\phi)-c_{M}^{b}-\sum_{m=1}^{M-1} c_{m}^{b}(1+\phi)= \\
& =c_{M}^{a}-c_{M}^{b}+(1+\phi)\left(\sum_{m=1}^{M-1} c_{m}^{a}-\sum_{m=1}^{M-1} c_{m}^{b}\right)>c_{M}^{a}-c_{M}^{b} .
\end{aligned}
$$

In the random matching scenario, in contrast, the monopolization takes place potentially slower since in each layer firms with different fitness are matched. Eventually, one of the VCs certainly dominates the other one (as long as its total unit cost is lower), but 



Figure 2: Dynamics with ordered and random matching

Note: The upper panel corresponds to ordered matching, while the lower one to random matching. $M=3$ and $N=3$.

this has a (negative) side effect in a sense of a less fit firm in one (or more than one layer) dominating with its market share its counter-partners. To illustrate that, consider Figure 2. The leftmost charts in the upper and lower panels display the differences in the speed of market reallocation for ordered and random matching, respectively; the overall selection dynamics among the three different value chains looks rather similar, except that the final winner is different. The mid charts show $\mathrm{VC}$-wise the corresponding dynamics with respect to changes in the average total unit costs $\bar{C}_{M}^{j} \cdot \sqrt[4]{4}$ Finally, the rightmost charts in Figure 2 show layer-wise the development on each of the three markets. In case of ordered matching, the dominating VC1 is built up by the dominating and hence best firms in each market (layer); these firms drive down the average $\bar{C}^{j}$ in each layer to the level of $\mathrm{VC1}$, just in line with replicator dynamics. Also in the random matching case the average $\bar{C}_{m}^{j}$ in each layer approaches that of the prevailing VC - in this case VC3. However, there the average fitness approached in each layer is not necessarily the 'best', as it should happen when the replicator dynamics holds. This is more evident when looking at the average fitness in layer 1, that increases in the first 200 simulation periods and then just returns to its original level. The integration into a value chain and the piling up of total unit costs as fitness indicator produces a dynamics that violates that standard replicator predictions. We name such violation a regressive development.

Analytically this can be supported in the following way. Remember that $\bar{C}_{m}=$ $\sum_{n=1}^{N} s^{n} C_{m}^{n}$ and given that in our particular case (through a random event) the second least fit firm from the first and third layers have been matched with the most fit firm in layer two, the total unit cost of that value chain (VC3 on the bottom mid chart of Figure 2 is lowest, and hence, it is merely a question of time when this value chain and

\footnotetext{
${ }^{4}$ Note that so far no innovation (in the sense of autonomous cost improvements by firms) is allowed and only the market share reallocation dynamics, by affecting the market-weighted average fitness, is driving the aggregate behavior of the model.
} 
effectively not fittest firms in layers one and three will dominate the market (see equation (5)). Hence, results stated above support our hypotheses from Section 2 and allow to formulate the following propositions:

Proposition 1 A firm with a fitness below the average of the market it is operating in may dominate it if it is integrated with highly fit partners from other layers, making the overall fitness of the value chain highest on the final end consumer market (layer $M$ ).

Proposition 2 The average fitness in upstream layers of a value chain can increase rather than decrease over time if upstream firms that are less fit than the average of the market they are operating in are linked to highly fit partners in downstream layers of the value chain. This dynamics violates the predictions of the standard replicator dynamics model and can be considered a regressive development of market selection driven by value chain relations.

Furthermore, we would like to stress that the famous Fisher's principle, stating that the change in average fitness, and hence the speed of market shares reallocation, in a population of competing firms is proportional to the variance in fitness, is also valid to this model of firms matched into value chains $5^{5}$ In particular, from Figure 2 one can see that the difference in aggregate fitness between value chains in case of ordered matching is higher (since all most fit firms are matched together against all least fit firms), and as a result, average total unit cost improvement and market share reallocation are taking place much faster. A similar effect can be also obtained under the following three conditions:

1. larger number of value chain layers $M$, but only for ordered matching. If one increases the number of layers $M$ from three to, e.g., ten, then for ordered matching the difference in aggregate fitness between the value chains measured by total unit costs $C_{M}^{j}$ will increase and domination of one value chain over other competitor chains will take place faster (see Figure 13 in the Appendix) ${ }^{6}$ This is because the term $\left(\sum_{m=1}^{M-1} C_{m}^{a}-\sum_{m=1}^{M-1} C_{m}^{b}\right)$ is increasing with every new layer of a value chain. For random matching scenario, in contrast, no difference should be obtained, since the value chains are matched randomly and on average shall contain for different $M$ the same portion of more $(a)$ or less $(c)$ fit agents:

$$
E\left[C^{j}\right]=\frac{c_{M}^{a}}{N}+\frac{c_{M}^{b}}{N}+\frac{c_{M}^{c}}{N}+\sum_{m=1}^{M-1}\left(\frac{c_{m}^{a}}{N}+\frac{c_{m}^{b}}{N}+\frac{c_{m}^{c}}{N}\right)(1+\phi) .
$$

Therefore, any difference in speed of market reallocation between bottom leftmost charts in Figures 2 13 is due to a random event (particular random VC matching) and not to any objective criterion.

\footnotetext{
${ }^{5}$ This strictly holds for the aggregate fitness (total unit cost) of VCs (since competition on the end consumer market defines market share reallocation, $\Delta \bar{C} \sim \sigma^{2}\left(C^{j}\right)$ ), but also — indirectly — for each market layer (since the variance in firm's fitness on each of the layers contributes to the respective variance of the value chains. For each single layer this, however, may not necessarily hold since even though there is a low variance in fitness, e.g., on layer one, the market share reallocation may still be high and equal in speed for all layers due to high variance in fitness on other layers.

${ }^{6}$ Note here that we keep the variance in unit cost fixed in each layer, and increasing $M$ naturally leads to larger differences between value chains.
} 
2. larger profit margin $\phi$ since it increases the variance in fitness on the final layer $M$ (see 6 7) similarly affecting both matching scenarios (Figure 14 in the Appendix).

3. larger variance in fitness between firms on any layer. Increasing the variance in fitness between firms on any layer $\left(\sigma^{m}\right)^{2}=\sum_{n=1}^{N}\left(C_{m}^{n}-\bar{C}\right)$ in our model, one increases the differences in expected total unit costs between the value chains, which automatically leads to faster market reallocation process. This result holds for both, ordered and random matching scenarios (Figure 15 in the Appendix).

\subsection{Random Value Chain Matching With Innovation}

In this section we extend the model by allowing firms to endogenously improve their specific fitness (that is, to reduce their layer-specific unit costs) through innovative activities.

The selection dynamics becomes in this way affected by two different and interacting forces acting on two distinct levels: on the one hand, the market reallocation based on the VC-dependent fitness (that is, on the total unit cost variable); on the other hand, firms' innovation activities resulting in performance improvements based on each specific layer (market). The distinction of the level of analysis at which selection and innovation operate is justified by the fact that it captures the real-world behavior of firms. In fact, in each layer firms compete on the basis of their total cost of production - that is function also of all the prices payed on each stage for intermediate supplies - but take efforts in order to improve their own idiosyncratic processes and products. In a nutshell, we include now in the model both the between (competition) effect and the within (learning/innovation) one. Our main contribution is to condition the reallocation on the VC structure, making the case for the replicator dynamics to work in unexpected ways. In what follows, we adopt three alternative specifications of cost-reducing innovation process: with constant, decreasing and increasing returns to scale (henceforth, CRS, DRS and IRS, respectively). Following Mazzucato (1998), this is done by setting

$$
\begin{aligned}
c_{m}^{j, t+1}=c_{m}^{j, t}(1-\gamma) & \text { for constant returns } \\
c_{m}^{j, t+1}=c_{m}^{j, t}\left(1-\gamma\left(1-s_{m}^{j, t}\right)\right) & \text { for decreasing returns } \\
c_{m}^{j, t+1}=c_{m}^{j, t}\left(1-\gamma s_{m}^{j, t}\right) & \text { for increasing returns. }
\end{aligned}
$$

All these specifications of technological progress are a function of an exogenous rate of technical improvement (cost reduction) $\gamma$ reinforced, dampened or neutrally-affected by firm size (measured by the market share). The possibility of cost reduction with CRS, as expected in accordance with the standard replicator model, creates the possibility of more than one value chain staying on the market (see leftmost charts in Figure 3).

Since in the ordered matching, the difference in total VC unit costs between the value chains is originally larger, the dominating value chain achieves a higher market share than in the case of random matching. The fact that the less fit firm obtains an advantage through linkages with strong partners in other layers can also be seen from Figure 3 . The dynamics of the average fitness in each layer, as shown in the rightmost charts, tends to be similar in the ordered and in the random matching. However, its interpretation becomes less trivial. In fact, the reduction in average total unit costs in each layer can be driven by two dynamics: if the initially fittest firm gains market shares, then average layer fitness decreases. On the other hand, even if a non-fittest firm, linked with fitter firms in other 
layers, gains market shares, the average layer's fitness may decrease instead of decreasing if the magnitude of cost-reducing innovative activities prevails over the increasing weight of the non-fittest firm's cost in the calculation of the average layer fitness. In other words, the within and the between effects may compensate each other and hide the tendency of market selection to work in the 'wrong way'. In order to disentangle these two related dynamics affecting selection, we turn to a decomposition exercise.

We consider the following decomposition of the change in market weighted average total unit cost in layer $m$ :

$$
\begin{aligned}
\Delta \bar{C}_{m}^{t} & =\bar{C}_{m}^{t}-\bar{C}_{m}^{t-1}=\sum_{i} s_{m}^{i, t} C_{m}^{i, t}-\sum_{i} s_{m}^{i, t-1} C_{m}^{i, t-1}= \\
& =\sum_{i}\left(s_{m}^{i, t} C_{m}^{i, t}-s_{m}^{i, t-1} C_{m}^{i, t-1}\right)=\sum_{i}\left(\left(s_{m}^{i, t-1}+\Delta s_{m}^{i, t}\right)\left(C_{m}^{i, t-1}+\Delta C_{m}^{i, t}\right)-s_{m}^{i, t-1} C_{m}^{i, t-1}\right)= \\
& =\sum_{i}\left(s_{m}^{i, t-1} C_{m}^{i, t-1}+s_{m}^{i, t-1} \Delta C_{m}^{i, t}+\Delta s_{m}^{i, t} C_{m}^{i, t-1}+\Delta s_{m}^{i, t} \Delta C_{m}^{i, t}-s_{m}^{i, t-1} C_{m}^{i, t-1}\right)= \\
& =\sum_{i} s_{m}^{i, t-1} \Delta C_{m}^{i, t}+\sum_{i} \Delta s_{m}^{i, t} C_{m}^{i, t-1}+\sum_{i} \Delta s_{m}^{i, t} \Delta C_{m}^{i, t}+0= \\
& =\sum_{i} s_{m}^{i, t-1} \Delta C_{m}^{i, t}+\sum_{i} \Delta s_{m}^{i, t} C_{m}^{i, t-1}+\sum_{i} \Delta s_{m}^{i, t} \Delta C_{m}^{i, t}+\sum_{i} \Delta s_{m}^{i, t} \bar{C}_{m}^{i, t-1}= \\
& =\sum_{i} s_{m}^{i, t-1} \Delta C_{m}^{i, t}+\sum_{i} \Delta s_{m}^{i, t}\left(C_{m}^{i, t-1}-\bar{C}_{m}^{i, t-1}\right)+\sum_{i} \Delta s_{m}^{i, t} \Delta C_{m}^{i, t} .
\end{aligned}
$$

Where any $\Delta C_{m}^{i, t}=\Delta \sum_{m=1}^{M-1} c_{m}^{j}(1+\phi)+\Delta c_{m}^{i, t}$, that is the total unit cost of a firm, changes as a result of innovation in all the suppliers' layers and in its own specific production process. The first term in equation (11) captures the within effect (the sum over all the individual firms cost changes each multiplied by the market share before the change in fitness), the second term - the between effect (the sum of market share changes weighted by the deviation of a firm's cost level from the market-weighted mean cost level of all firms - that is basically the replicator term we are most interested in), while the third term is the so-called covariance effect (which being negative indicates that the selection is faster than predicted by the replicator mechanism alone, while its positive value is associated with slower selection compared to the replicator dynamics mechanism (Cantner and Krüger, 2008)). The covariance component captures the dynamics returns to scale introduced by innovative activities. For the standard replicator dynamics to hold the second term (the between effect) has to be negative for each market, i.e. each firm being less productive than market average should decrease its market share.

The corresponding decompositions into the within, between and covariance effects are reported in Figure 4. Clearly, while in the ordered matching the between effect is consistently negative and of comparable magnitude with the within effect in all three layers, the pattern is very different for the random matching. In particular, the between effect becomes much smaller in absolute terms and turns to be positive in the layer one, indicating that in this market a firm integrated in a strong $\mathrm{VC}$ was increasing its market share although its fitness was below the market average. Hence, from the decomposition exercise it becomes clear that the replicator dynamics does not necessarily hold in markets that are vertically related (again supporting the hypotheses stated earlier) $]^{7}$

\footnotetext{
${ }^{7}$ Note that in the former exercise with no innovation the within and covariance effect are zero, as there is no change in layer-specific unit costs over time. The between effects however are present and also occasionally turn to be positive in one or the other layer in the random matching scenario.
} 

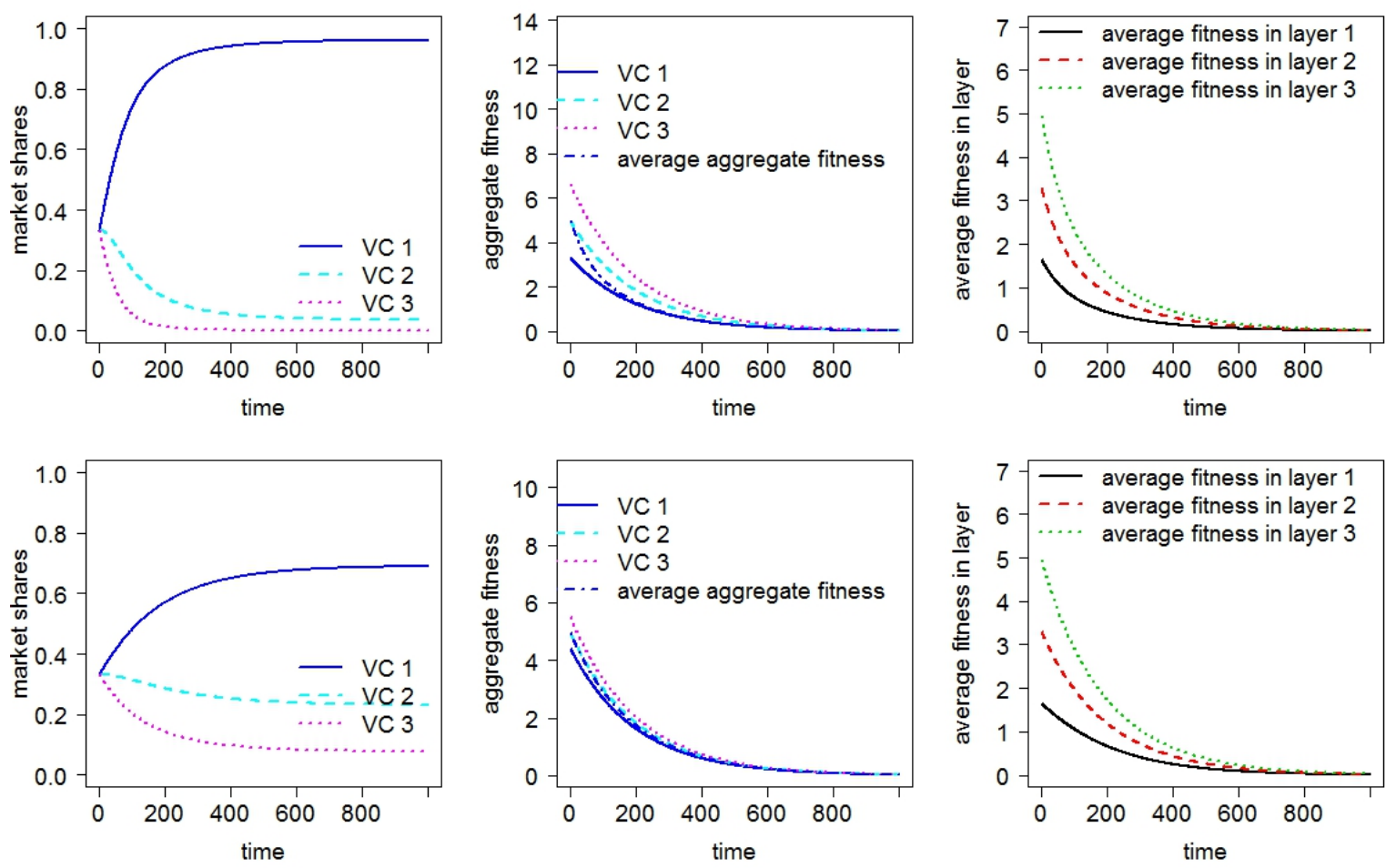

Figure 3: Dynamics with ordered and random matching and innovation with CRS Note: The upper panel corresponds to ordered matching, while the lower to random matching. $M=3, N=3$ and $\gamma=0.005$.


Figure 4: Decomposition of change in average unit cost with CRS

Note: The upper panel corresponds to ordered matching, while the lower to random matching. From the left to the right the markets (layers) 1,2 and 3 are shown. 
For decreasing returns to scale: Setting the rate of cost reduction to be inversely proportional to market share, one obtains a typical pattern of high volatility of market shares in the initial period. This volatility is (potentially) higher in the ordered matching, where the differences in fitness between the value chains are higher (Figure 5). The corresponding contribution of the within, between and covariance effects to the change in market weighted average fitness is presented in Figure 6. Again, the between effect is close to zero and occasionally turns positive in the random matching scenario, but not in the ordered matching one.

For increasing returns to scale: As it is typical for IRS, a random event (in terms of slightly lower layer-specific unit cost at the beginning of simulation) defines which of the value chains will dominate the others. Once firms start innovating, evolution of unit costs and market shares (at least for the leading VC) proceeds much faster than in the scenario with constant returns to scale (Figure 7). The process of market monopolization is taking place again faster in ordered matching as the initial advantage of the fittest value chain over its counterparts is larger. Similarly, the decomposition in the between, within and covariance effects demonstrates that in one of the layers (here layer one) the between effect deviates from the prediction, being positive in the first three hundred periods (Figure 8). One can conclude that also under IRS a less fit firm integrated in a superior VC gets an opportunity to improve its fitness rank to the level of the partners.
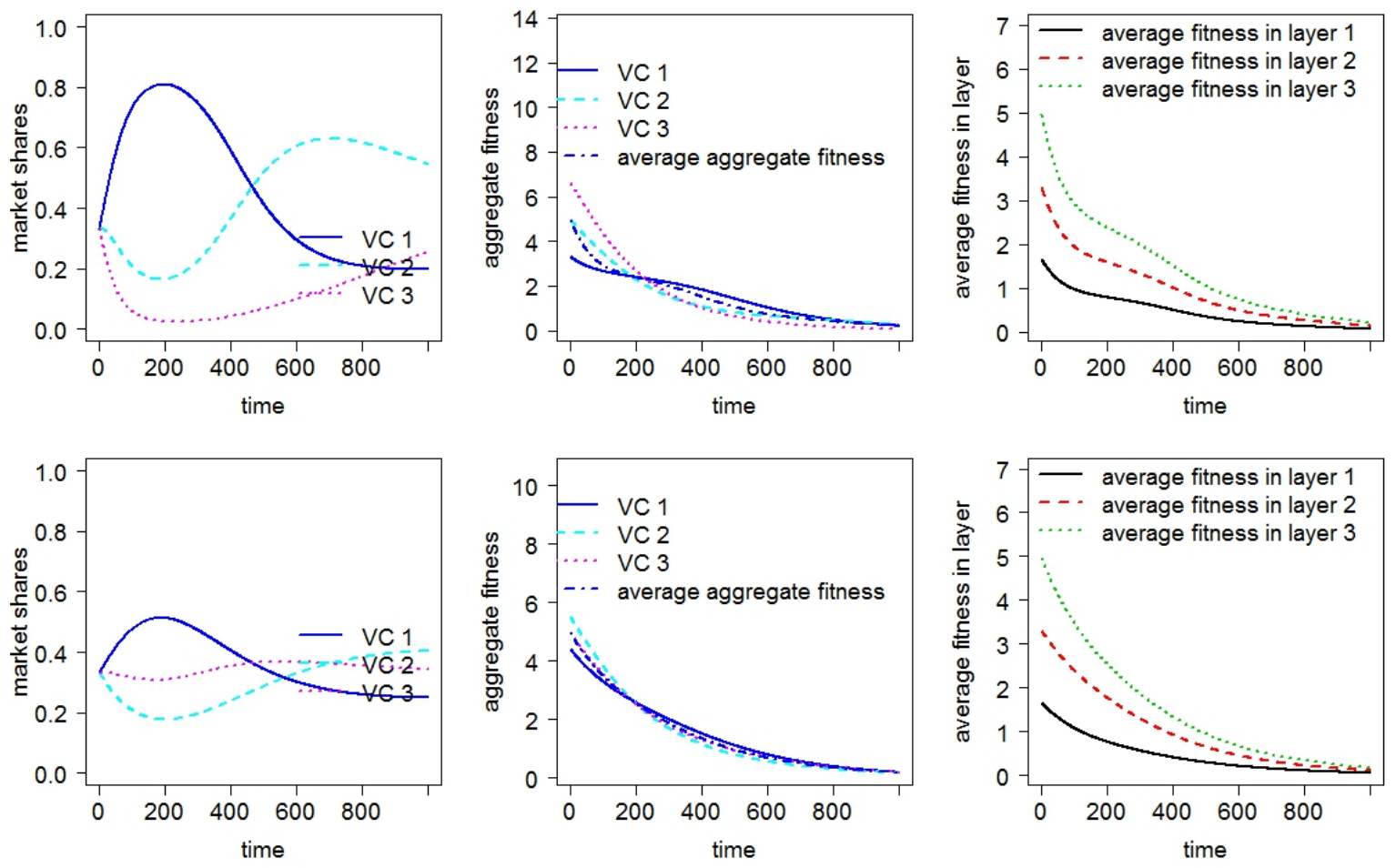

Figure 5: Dynamics with ordered and random matching and innovation with DRS Note: The upper panel corresponds to ordered matching, while the lower to random matching. $M=3, N=3$ and $\gamma=0.005$. 

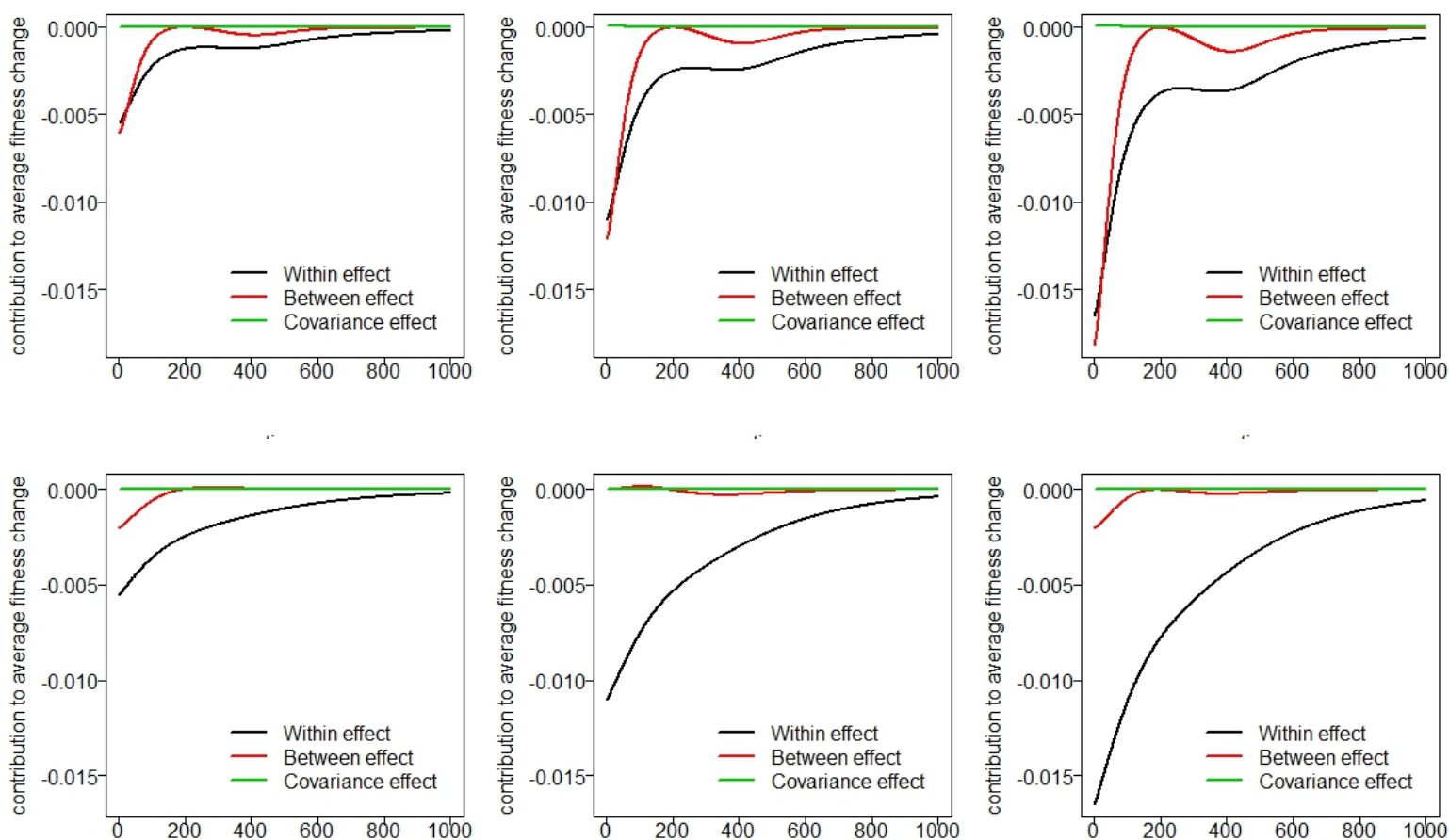

Figure 6: Decomposition of change in average unit cost with DRS

Note: The upper panel corresponds to ordered matching, while the lower to random matching. From the left to the right the markets (layers) 1, 2 and 3 are shown.
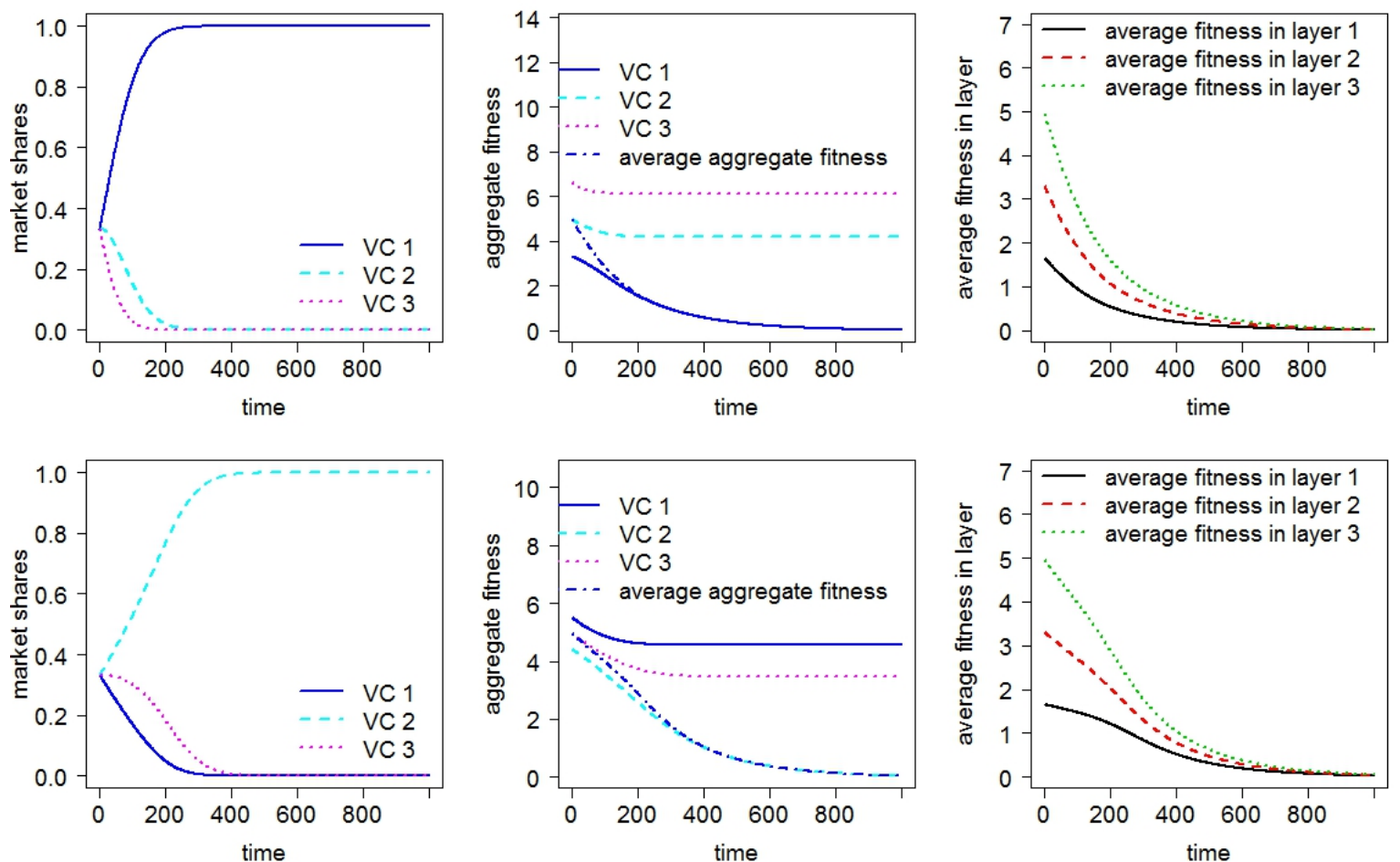

Figure 7: Dynamics with ordered and random matching and innovation with IRS Note: The upper panel corresponds to ordered matching, while the lower to random matching. $M=3, N=3$ and $\gamma=0.005$. 

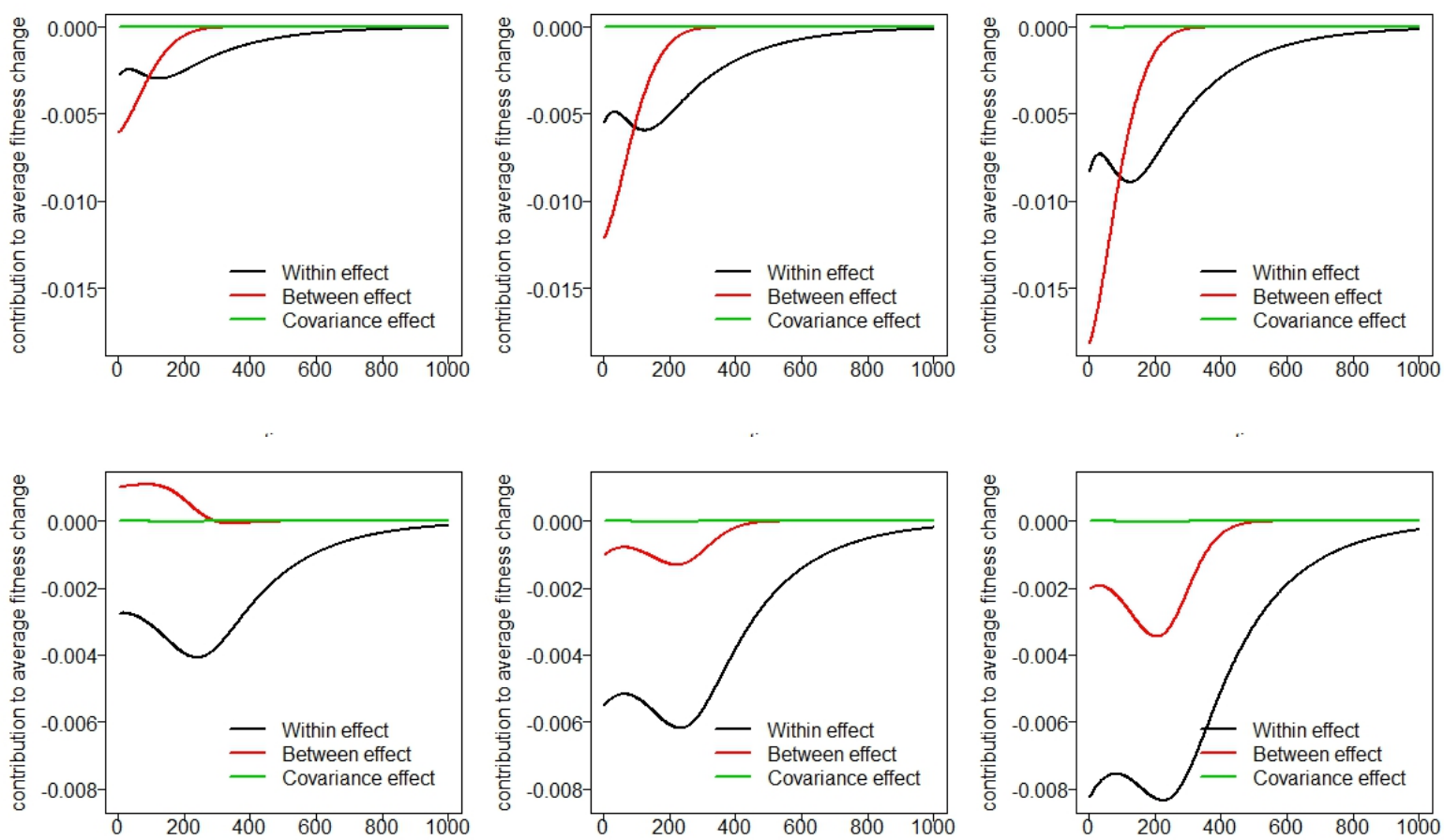

Figure 8: Decomposition of change in average unit cost with IRS

Note: The upper panel corresponds to ordered matching, while the lower — to random matching. From the left to the right the markets (layers) 1,2 and 3 are shown.

\subsection{Possibility of Partner Switching}

While in in the previous two exercises the value chains were assumed to be fixed due to prohibitively high switching cost, one could relax that assumption. 8 Switching costs may involve simply a fixed cost $S C$, and those firms which either compensate this cost by gaining lower price of a new supplier multiplied by existing orders or gaining more orders requested by new downstream partner at the current price, will be willing to switch. We propose to model $S C$ as percentage parameter: a firm is willing to switch a partner if it gains in fitness at least a certain percentage from the current fitness level, e.g., if the new supplier has a lower price than the old one.

To account for the fact that a firm can switch only if there is reciprocity from the other side (potential partner finds it also attractive to switch to that firm), we introduce a simple search and acceptance algorithm ensuring reciprocity. In particular, if a firm $j$ from a layer $m_{1}$ in a value chain $\mathrm{x}\left(V C^{x}\right)$ considers to switch its current partner $j j$ from a layer $m_{2}$ (which can be either $m_{1}+1$ or $m_{1}-1$ ) and takes (randomly) firm $j k \neq j j$ from a different value chain $V C^{y}$ into consideration (which in its turn has currently a partnership with firm $k k$ from layer $m_{1}$ ), then those two firms, $j$ and $j k$, will do the switching iff the fitness of the part of the value chain $V C^{y}$ (firm $j j$ from the layer $m_{2}$ is currently integrated in) $j$ is switching to is better than the fitness of the corresponding part of $V C^{x}$, while the opposite holds true for the remaining parts of those two VCs:

\footnotetext{
${ }^{8}$ The possibility to switch partners in a value chain is less unrealistic than it may appear at a first sight; the whole worldwide structural re-organization or production around global value chains is the most recent example that vertical relations between industries are neither completely frictionless nor totally rigid.
} 
the fitness of the remaining part of $V C^{y} j k$ is integrated to is worse in fitness than the corresponding part of the $V C^{x} j$ is integrated to (see Figure 9).9

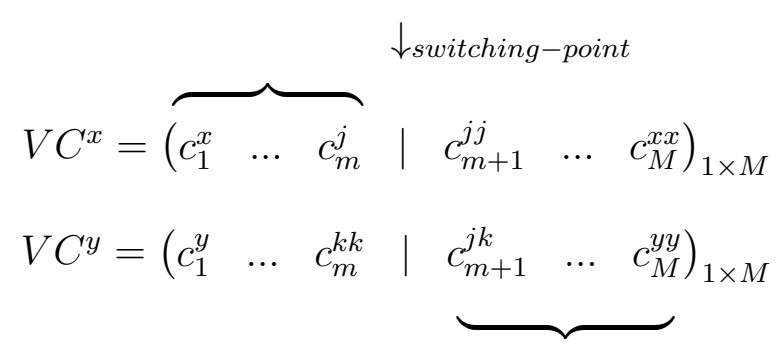

Figure 9: Comparison of fitnesses for switching

Necessarily, the parameter of switching cost $S C \in[0,1]$ becomes a key parameter, allowing situations from 'fast and easy' switching for the two firms as if no sunk costs of partnership formation exist (close to frictionless markets on upstream layers) to no switching (and respectively, no competition) at all. In what follows, we refer to a simplified case $(M=3$ and $N=3)$ and to a more general case $(M=10$ and $N=10)$. Figures are given for the simplified case, while the more general case is presented in the Appendix.

As in the ordered switching scenario fittest firms in the respective layers are matched together, there is basically no room left for switching. In contrast, in case of random value chain matching, firms occasionally switch (no matter whether innovative activity is present and if yes, in which scenario of scale returns). The moment of switching can be captured by the 'zig-zag' evolution (abrupt shifts) of the total unit costs of the VCs (mid-charts in all four panels of Figure 10) and the corresponding adjustments in the evolution of VC market shares (leftmost charts of the same figure) ${ }^{10}$

As a result, in early periods of simulation (which can be interpreted, for example, as early stage of an industry life-cycle) one observes a period of volatility in the market share constellation (for a better visualization consider a more complex scenario with $M=10$ and $N=10$, Figure 16 in Appendix). Except for the scenario with DRS, a dominating VC is identified relatively quickly, driving other VCs outside the market and killing any volatility in market shares dynamics. The observation on the DRS scenario is not surprising, as by design DRS is meant to preserve competition between actors for a longer period of time. What is more interesting is that the market share volatility in early periods is more universal and not so sensitive to scale returns, contrasting to the earlier argument made by Mazzucato (1998) that high volatility in the early period of life-cycle is to be found only for DRS.

Proposition 3 Considering random matching scenario of firms vertically integrated in VCs and allowing them to switch, one observes a high volatility in market share dynamics at the beginning of the simulation (corresponding to early period of industry life-cycle) irrespective of the specific return to scale mode.

\footnotetext{
${ }^{9} \mathrm{We}$ also considered a simpler option of switching a partner when the randomly drawn candidate has a better fitness than our current partner, i.e. $c_{m_{2}}^{j j}-c_{m_{2}}^{j k}>S C \times c_{m_{2}}^{j j}$ and $c_{m_{1}}^{k k}-c_{m_{1}}^{j}>S C \times c_{m_{1}}^{k k}$. But given that this rule ignores the fitness of other partners integrated in VCs, such a rule is an oversimplification of reality and results in a much larger number of partner switches. The overall result (in terms of market reallocation and fitness improvement) is, however, consistent with our preferred acceptance algorithm.

${ }^{10}$ Since for ordered matching the possibility of switching is never exploited, we do not include the related charts.
} 

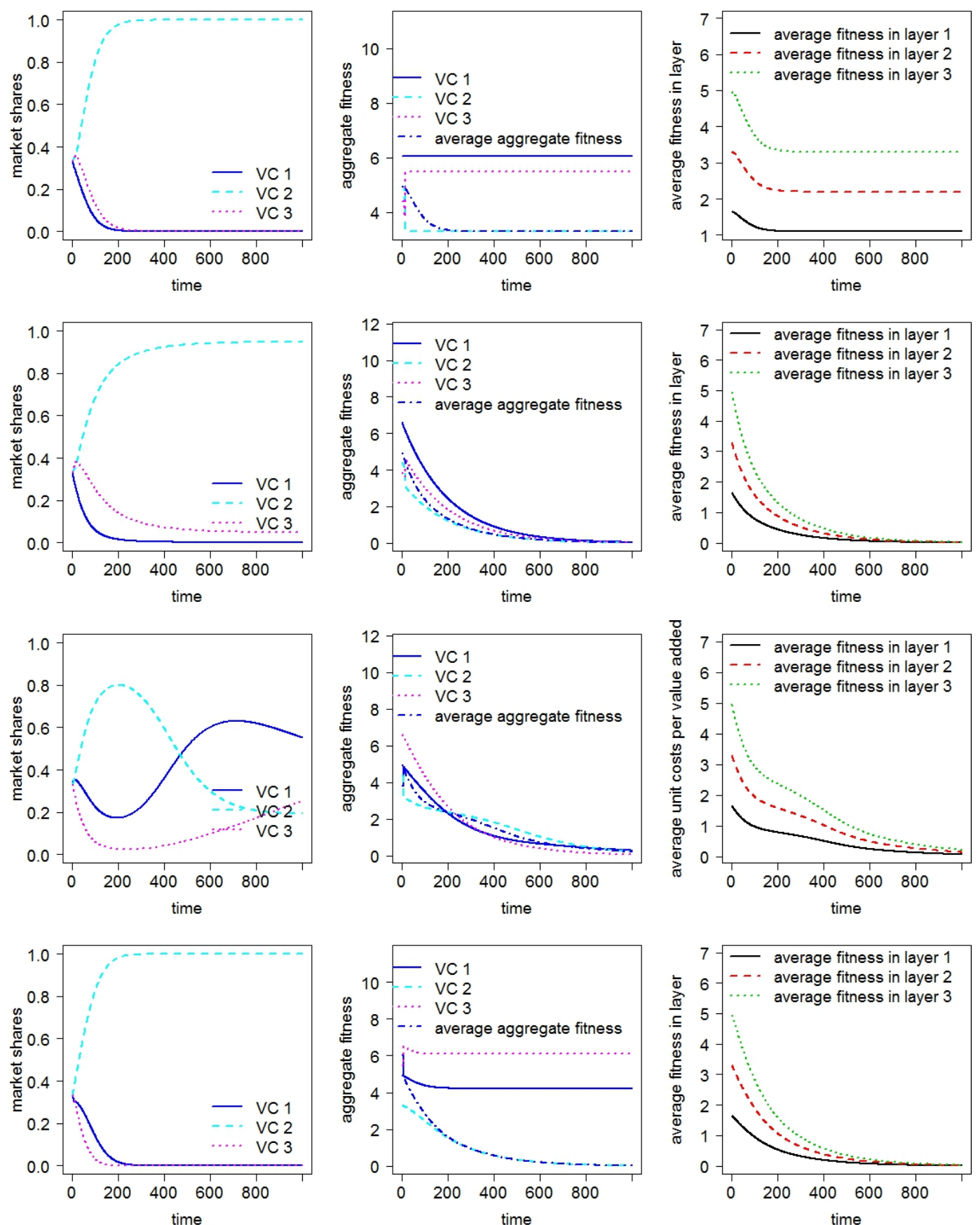

Figure 10: Dynamics with random matching, different innovation scenarios and switching Note: The upper panel corresponds to no innovation, the next to innovation with CRS, the third from the top to innovation with DRS, and the bottom one to innovation with IRS. $M=3, N=3, S C=10 \%$ and $\gamma=0.005$.

In Figure 11 one can find the corresponding decompositions into the between, within and covariance effects for the four scenarios with switching. Given that the firms in the VCs are connected via constant quantity relations (the firm in the last market competes for an output quantity (market share) and the upstream firms serve as suppliers of intermediary products for this final quantity), a switch of a $\mathrm{VC}$ partner implies a large change in the output quantity producing an instantaneous shock, which takes place synchronously on all $M$ layers, but with different magnitudes. ${ }^{11}$

\footnotetext{
${ }^{11}$ This is due to the different deviation of each VC member's layer-specific cost level from the market-
} 

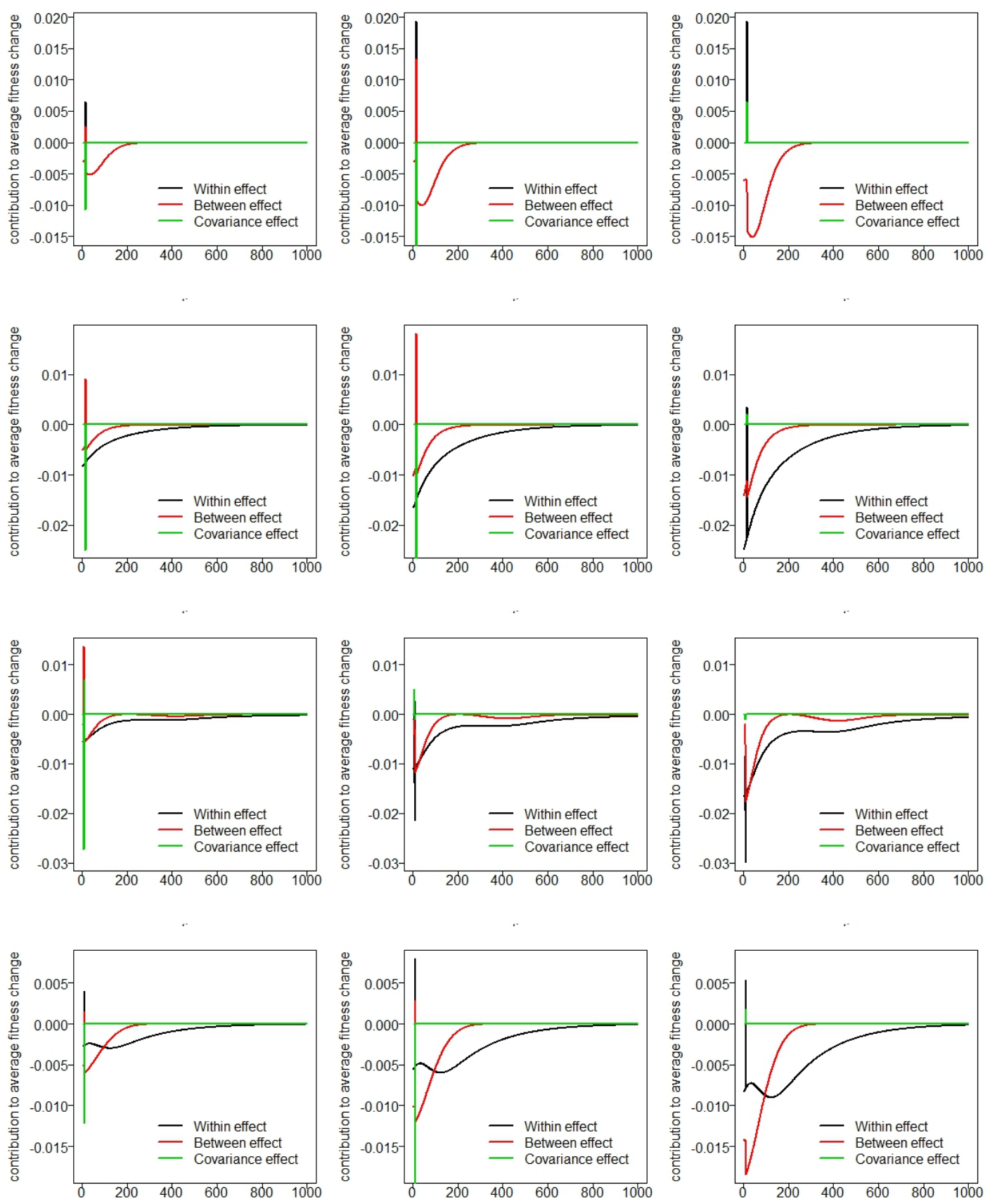

Figure 11: Decomposition of change in average unit cost for different innovation scenarios and switching

Note: The upper panel corresponds to no innovation, the next to innovation with CRS, the third from the top to innovation with DRS, and the bottom one to innovation with IRS.

Thus, firms in the up- or downstream part of VC having switched to a stronger group of partners experience a sudden increase in their market share. Given that by construction switching requires reciprocity and more fit firms tend to build stronger VCs, most of the time firms gaining additional market shares have a cost below their market average, which results in negative shocks. As a result, we observe those negative shocks in the between effects, depicted by the red line in Figure 11. Those shocks clearly correspond weighted mean layer-specific cost level, see (11). 
to the moments when switching takes place and are concentrated in the early periods of simulation (see also Figure 17 in the Appendix).

The main reason why the switches (and the corresponding shocks in the between effect) tend to take place so early is that the cost differences in the early phases are stronger (this holds true for all scenarios with innovation) so that the term indicating the deviation from the cost average $\left(C_{m}^{i, t-1}-\bar{C}_{m}^{i, t-1}\right)$ is also stronger. The other reason distinguishing somewhat the simplified and the the more general cases is that the total number of possible 'reconfigurations' of the value chains, though being different becomes quickly exploited within the first few hundred periods of the simulation run.

\subsection{Summary on the Average Unit Cost Decomposition}

To better summarize the differences between scenarios considered in terms of the average layer-specific unit cost decomposition, consider Table 1, where the three effects are averaged over all $M$ (here $M=10$ and $N=10$ are taken as default) layers and all $T$ (as before, equal to 1000) periods for 1000 restarts. Comparing the left and right hand side of the table one immediately notices that the between effect in the random matching is consistently less strong than in ordered VC matching, which is due to the fact that only in some markets the replicator dynamics works in the 'right' way, while in others - firms performing worse than market average but integrated in stronger VCs improve their market position. Notably, in the random matching scenario the within effect clearly dominates the between effect in all but no innovation scenario ${ }^{12}$ Such result generally supports our idea that the clear-cut expected results of market selection are made more ambiguous by the learning and innovation processes 13

Looking at the results with the possibility of switching partners within a value chain (second and third panels in Table 1), we observe the following outcomes for the random matching case:

1. in the scenario with no innovation, the possibility of switching hastens fitness improvement. This result is logical as one can recombine the structures of a $\mathrm{VC}$ in a more efficient way than the original random structure achieving a higher efficiency (compare lower panel of Figure 2 with the upper one in Figure 10). Increasing the cost of switching $S C$ to $50 \%$ (making it less frequent so that it takes place when both sides have very large benefits from changing their upstream/downstream partners), limits the possibility of VC 'optimization' and mitigates its effect on fitness improvement;

2. in the scenarios with innovation (CRS, DRS and IRS), no clear pattern is found, apart for the role of the between effect that increases for DRS when $S C=10 \%$. The within effect increases the more costly is the switch (as it becomes more costly

\footnotetext{
${ }^{12}$ Within effect directed on firm specific fitness here is certainly zero. However, since firm's total fitness includes costs of input, the within effect can deviate from zero due to switching. Note that comparing ordered and random matching in case of no innovation proves the between effects and the overall improvement to be always higher for the former case, which is consistent with our prediction.

${ }^{13}$ Another interesting observation from Table 1 is the fact that for DRS both for ordered and random VC matching the difference of the between and the within effects is largest, which is due to the fact that in this particular returns to scale scenario change in costs slows down due to increasing market shares and, as a result, one observes more dynamics in $\Delta s_{m}^{i, t}\left(C_{m}^{i, t-1}-\bar{C}_{m}^{i, t-1}\right)$ than in $s_{m}^{i, t-1} \Delta C_{m}^{i, t}$. In other words, in case of DRS firms reach a smaller progress in cost reduction but exhibit a larger market share reallocation dynamics, which reflects in larger values of the between effect.
} 
to improve VC competitiveness by partner switching and one has to rely more on internal improvements $(\mathrm{R} \& \mathrm{D}))$.

Summarizing the results above, we can outline the next proposition:

Proposition 4 For randomly matched value chains, the possibility of switching boosts the change in aggregate fitness in the case of no innovation. The possibility of partner switching and the cost of partner switching affect in different ways the working of the replicator dynamics, with the clearer positive effect on selection to be found in case of DRS and low switching costs.

Table 1: Results for the average unit cost decomposition over different scenarios

\begin{tabular}{|c|c|c|c|c|c|c|c|}
\hline & \multicolumn{3}{|c|}{ Ordered VC matching } & \multicolumn{3}{|c|}{ Random VC matching } \\
\hline & & Between Effect & Within Effect & Covariance & Between Effect & Within Effect & Covariance \\
\hline \multirow{8}{*}{ 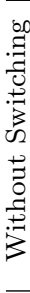 } & No innovati & -0.0136 & 0 & 0 & -0.0045 & 0 & 0 \\
\hline & No innovate & $(0.1174)$ & (0) & (0) & $(0.0251)$ & (0) & (0) \\
\hline & $\mathrm{CBS}$ & -0.0130 & -0.0067 & 0.0001 & -0.0038 & -0.0157 & 0.0000 \\
\hline & URS & $(0.1143)$ & $(0.0122)$ & $(0.0006)$ & $(0.0226)$ & $(0.0246)$ & $(0.0001)$ \\
\hline & DBS & -0.0155 & -0.0040 & 0.0000 & -0.0051 & -0.0143 & 0.0000 \\
\hline & DRS & $(0.1142)$ & $(0.0084)$ & $(0.0006)$ & $(0.0225)$ & $(0.0197)$ & $(0.0002)$ \\
\hline & IR & -0.0137 & -0.0059 & -0.0000 & -0.0051 & -0.0143 & -0.0000 \\
\hline & 115 & $(0.1173)$ & $(0.0081)$ & $(0.0000)$ & $(0.0254)$ & $(0.0186)$ & $(0.0001)$ \\
\hline \multirow{8}{*}{ 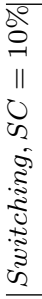 } & & -0.0136 & 0 & 0 & -0.0019 & 0.0089 & -0.0167 \\
\hline & No innovation & $(0.1174)$ & (0) & (0) & $(0.2726)$ & $(0.3$ & $(0.5540)$ \\
\hline & CBS & -0.0130 & -0.0067 & 0.0001 & -0.0035 & -0.0106 & -0.0055 \\
\hline & URs & $(0.1143)$ & $(0.0122)$ & $(0.0006)$ & $(0.1031)$ & $(0.1140)$ & $(0.2033)$ \\
\hline & $D B s$ & -0.0155 & -0.0040 & 0.0000 & -0.0079 & -0.0100 & -0.0014 \\
\hline & Dns & $(0.1142)$ & $(0.0084)$ & $(0.000$ & $(0.1072)$ & $(0.1257)$ & $(0.2181)$ \\
\hline & & -0.0137 & -0.0059 & -0.0000 & -0.0039 & -0.0080 & -0.0077 \\
\hline & IRS & $(0.1173)$ & $(0.0081)$ & $(0.0000)$ & $(0.1843)$ & $(0.1983)$ & $(0.3616)$ \\
\hline \multirow{8}{*}{  } & No innovatio & -0.0136 & 0 & 0 & -0.0043 & 0.0004 & -0.0008 \\
\hline & No innovatio & $(0.1174)$ & (0) & (0) & $(0.078$ & & $(0.1575)$ \\
\hline & CRS & -0.0130 & -0.0067 & 0.0001 & -0.0038 & -0.0156 & -0.0002 \\
\hline & Uns & $(0.1143)$ & $(0.0122)$ & $(0.0006)$ & $(0.0325)$ & $(0.0377)$ & $(0.0516)$ \\
\hline & DR & -0.0155 & -0.0040 & 0.0001 & -0.0051 & -0.0142 & -0.0000 \\
\hline & & $(0.1142)$ & & $(0.0006)$ & $(0.0269)$ & $(0.0285)$ & $(0.0366)$ \\
\hline & IRS & -0.0137 & -0.0059 & -0.0000 & -0.0048 & -0.0135 & -0.0012 \\
\hline & ins & $(0.1173)$ & $(0.0081)$ & $(0.0001)$ & $(0.0920)$ & $(0.0999)$ & $(0.1813)$ \\
\hline
\end{tabular}

Note: Results are averaged over 1000 restarts for all vertically integrated layers and time periods. Standard deviations are reported in parentheses.

It is useful at this point to analyze how the between, within and covariance effects vary between the layers of a value chain. We investigate how the disproportion in distribution of the between, within and covariance effects between layers changes with respect to the number of layers considered, experimenting with the cases featuring three, five, seven and nine layers (keeping the number of layers odd to simplify selection of the 'mid' layers, $\frac{M-1}{2}+1$ following the notation used so far). Results of the experiment are presented in Figure 12. In general, the pattern that emerges is one in which - both in ordered and random matching - the between effect is stronger for layers being closer to the final market. In fact, all three type of effects are concentrated on the bottom $(M)$ layer, while with the increasing number of layers the disproportion in the distribution of the effects increases consistently. This is particularly pronounced for the CRS and DRS cases, where the within effects are about five times bigger (in case of nine layers) in the bottom layer compared to the upper layer. The fact that different layers are heterogeneously affected 
by selection dynamics provides a matter of discussion for policy and in particular for competition policy. Markets that are linked in value chains require different sets of policy measures according to the strength of competition and reallocation. At the same time, knowing the heterogeneous magnitudes of selection dynamics in different layers of the value chains may affect firms' strategic decisions regarding the establishments of specific value chain linkages.
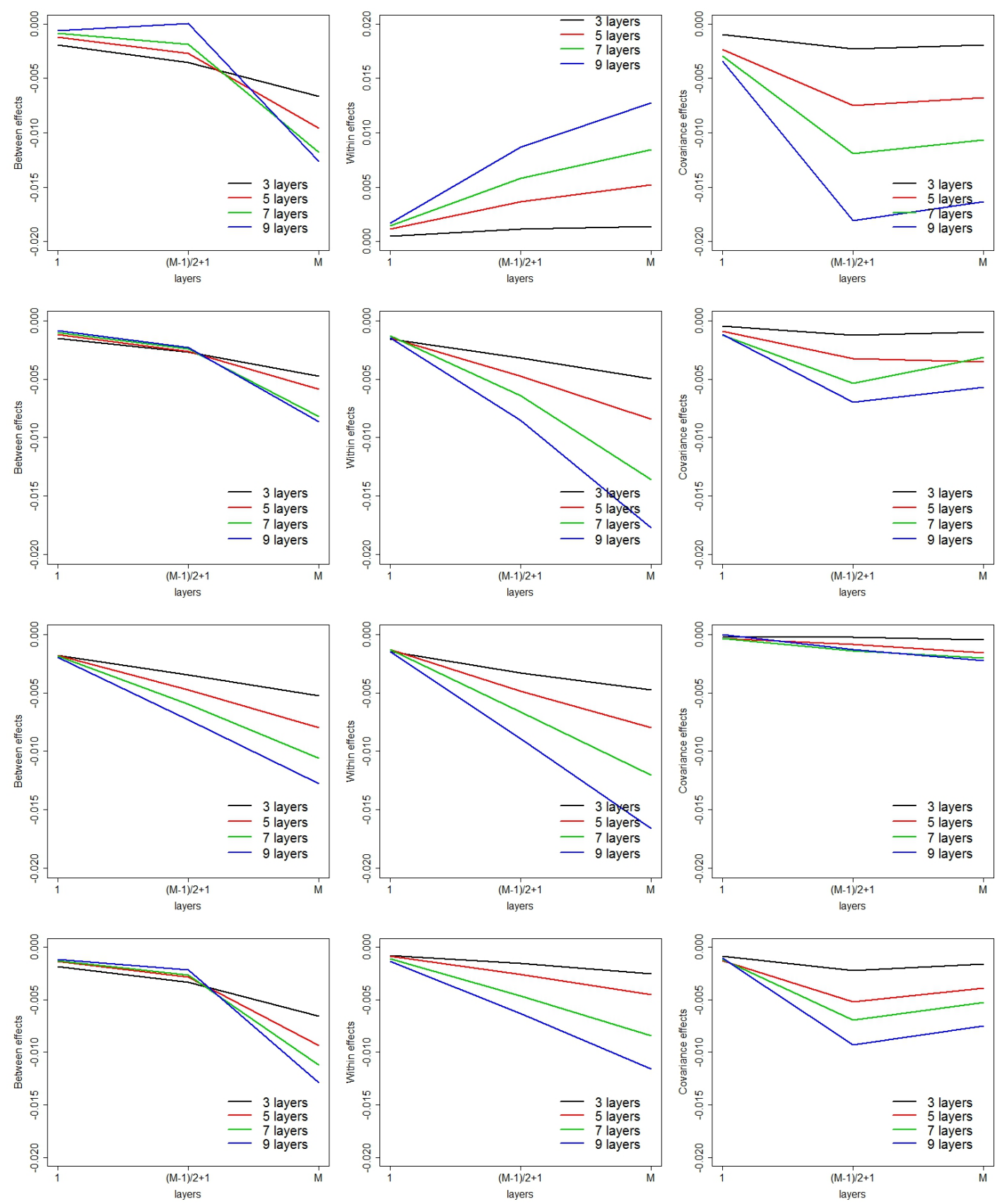

Figure 12: Dynamics in the decomposition into between and within effects for different number of layers

Note: The upper panel corresponds to no innovation, the next to innovation with CRS, the third from the top to innovation with DRS, and the bottom one to innovation with IRS. $M=10, N=10$ and $S C=10 \%$.

This experiment on the distribution of the within, between and covariance effects with respect to the number and position of the VC layers leads to the fifth result: 
Proposition 5 For all the types of value chains, selection affects different layers (markets) in different ways. More specifically, the replicator dynamics intensifies its effect the closer the layer is to the final market. The heterogeneous distribution of selection effects across value chain's layers has implications for competition policy, that may discriminate firms according to their position in the value chains, and for firms' strategic decision on value chain positioning.

\section{Conclusion}

In this paper we generalize the replicator dynamics model to the case of firms vertically related in value chains. For that we conduct a series of exercises starting from the most simplest one without innovation to three innovation cases and increasing the complexity stepwise. Doing this, we contrast two scenarios with firms being matched according to the performance rank of its members (ordered matching scenario) and those being matched completely randomly. In addition, we introduce a simple rule of partner switching ensuring reciprocity from both sides. Then, using some analytical but mainly computational tools, we show how the two scenarios differ.

Our exercise results in Propositions 1 15. First of all, we demonstrate that firms being related into VC structure and being dependent in their output capacity on their downstream partners do not necessarily increase their market share even though being most efficient that is, having higher (lower) fitness (total unit cost)) on their respective layers. This is due to the limited competition on upstream markets (firms being locked-in into $\mathrm{VCs}$ ) and the aggregate fitness of a VC being crucial for the success on the final consumer market. Thus, the very existence of $\mathrm{VC}$ relations may induce violations of the replicator dynamics generating what we called regressive developments of market selection; in these situations the average fitness may decrease rather than increase over time.

Furthermore, we show that for firms in the random VC matching scenario with the possibility to switch partners produces at the beginning a period of high market share volatility dynamics in any innovation and returns to scale setting, which provides a novel and simpler explanation to the evidence discussed by Mazzucato (1998).

Our two last results indicate that the possibility of partner switching, coupled with different 'regimes' of switching costs, hastens the change in aggregate fitness (for randomly matched value chains) and affects with various intensities selection dynamics. Moreover, market selection affects with different magnitudes different value chains layers, with the strongest effect to be found at the final (end consumer) market of the value chain. The latter results may be taken into consideration to derive policy implications. Although policy makers have generally limited influence on firms' strategic decisions with regard to partner selection, certain measures such as increasing market transparency or financial support for firms at the early period of alliance formation may come in question to facilitate the 'survival of the fittest' principle and to support productivity improvement on a given market.

Our results call both for more differentiated analyses of the replicator dynamics on different stages of value creation ${ }^{14}$ and possibly different competition policy measures applied for different markets. In general, the idea that market selection may 'bite' more in cer-

\footnotetext{
${ }^{14}$ Thus, while it may be easier to find evidence for the replicator model on the downstream market, such as stage of assembling and selling compact cars, it is more challenging for producers of intermediate parts, and one has to take this into account.
} 
tain layers of a value chain opens two broad sets of research questions. First, how should policy interventions (targeting innovation and competition) focus more on upstream and downstream bottlenecks rather than just looking at a single layer rate of innovation and production? Second, how was the current reconfiguration of production into global value chains (Timmer et al., 2014) affected by (and can affect) the Schumpeterian competition for the market?

For further research we plan to explore at least the two following trajectories. First, to deepen our understanding and identification of the VC structures under which the replicator dynamics is violated and regressive developments take place. Second, to generalize the exercise allowing firms to partner more than one firm from the same layer at the same time. This should allow to address network properties of production chains. Furthermore, one can draw better intuition on differences between layers in terms of their alliance formation power and firm survival.

As a conclusion, by introducing value chains into the mechanism of market selection, our contribution sheds a light on the multidimensional nature of the replicator dynamics model; instead of confining it among the theoretically elegant but empirically irrelevant economic tools, we hope this will induce new attempts to enrich its framework and understand its validity and explanatory power.

\section{References}

Baily, M. N., C. H. and Campbell, D. (1992). Productivity dynamics in manufacturing plants. Brookings Papers on Economic Activity. Microeconomics, 187-26\%.

Bartelsman, E. J. (2010). Searching for the sources of productivity from macro to micro and back. Industrial and Corporate Change, 19(6):1891-1917.

Bottazzi, G., Secchi, A., and Tamagni, F. (2008). Productivity, profitability and financial performance. Industrial and Corporate Change, 17(4):711-751.

Bresnahan, T. F. and Levin, J. D. (2012). Vertical integration and market structure. Technical report, National Bureau of Economic Research.

Cantner, U. (2014). Evolution of markets. Technical Report mimeo, Friedrich Schiller University Jena.

Cantner, U. and Krüger, J. (2008). Micro-heterogeneity and aggregate productivity development in the German manufacturing sector: Results from a decomposition exercise. Journal of Evolutionary Economics, 18(2):119-133.

Cantner, U., Krüger, J., and Söllner, R. (2012). Product quality, product price, and share dynamics in the German compact car market. Industrial and Corporate Change, 21(5):1085-1115.

Coad, A. (2007). Testing the principle of 'growth of the fitter': The relationship between profits and firm growth. Structural Change and Economic Dynamics, 18(3):370-386.

Dosi, G., Moschella, D., Pugliese, E., and Tamagni, F. (2015). Productivity, market selection and corporate growth: comparative evidence across US and Europe. Small Business Economics, forthcoming. 
Foster, L., Haltiwanger, J., and Syverson, C. (2008). Reallocation, firm turnover, and efficiency: Selection on productivity or profitability? American Economic Review, 98(1):394-425.

Foster, L., Haltiwanger, J. C., and Krizan, C. J. (2001). Aggregate productivity growth. lessons from microeconomic evidence. In New developments in productivity analysis, pages 303-372. University of Chicago Press.

Friedman, M. (1953). The methodology of positive economics. In Friedman, M., editor, Essays in Positive Economics, pages 3-43. University of Chicago Press, USA.

Griliches, Z. and Regev, H. (1995). Firm productivity in Israeli industry: 1979-1988. Journal of Econometrics, 65(1), 175-203.

Hölzl, W. (2015). Mobility barriers and the speed of market selection. Journal of Evolutionary Economics, 25:323-344.

Hopenhayn, H. A. (1992). Entry, exit, and firm dynamics in long run equilibrium. Econometrica: Journal of the Econometric Society, pages 1127-1150.

Jovanovic, B. (1982). Selection and the evolution of industry. Econometrica: Journal of the Econometric Society, pages 649-670.

Krüger, J. (2014). Intra-sectoral structural change and aggregate productivity development: a robust stochastic non-parametric frontier function approach. Empirical Economics, 46(4):1545-1572.

Maliranta, M. and Määttänen, N. (2015). An augmented static Olley-Pakes productivity decomposition with entry and exit: Measurement and interpretation. Economica. doi: 10.1111/ecca.12159.

Mazzucato, M. (1998). A computational model of economies of scale and market share instability. Structural Change and Economic Dynamics, 9(1):55-83.

Melitz, M. J. and Polanec, S. (2015). Dynamic Olley-Pakes productivity decomposition with entry and exit. The RAND Journal of Economics, 46(2):362-375.

Metcalfe, J. and Calderini, M. (2000). Chance, necessity and competitive dynamics in the Italian steel industry. In Cantner, U., Hanusch, H., and Klepper, S., editors, Economic Evolution, Learning, and Complexity, pages 139-158. Physica, Heidelberg, New York.

Metcalfe, J. S. (1994). Competition, fisher's principle and increasing returns in the selection process. Journal of Evolutionary Economics, 4(4):327-346.

Metcalfe, J. S. and Ramlogan, R. (2006). Creative destruction and the measurement of productivity change. Revue de l'OFCE, (5):373-397.

Nelson, R. and Winter, S. (1982). An Evolutionary Theory of Economic Change. Harvard University Press, Cambridge, MA.

Olley, G. S. and Pakes, A. (1996). The dynamics of productivity in the telecommunications equipment industry. Econometrica, 64(6):1263-1297. 
Schuster, P. and Sigmund, K. (1983). Replicator dynamics. Journal of theoretical biology, 100(3):533-538.

Silverberg, G. (1997). Evolutionary modeling in economics: recent history and immediate prospects. MERIT Research Memoranda, 8.

Strader, T., Lin, F., and Shaw, M. (1998). Simulation of order fulfillment in divergent assembly supply chains. Journal of Artificial Societies and Social Simulation, 1(2).

Timmer, M. P., Erumban, A. A., Los, B., Stehrer, R., and de Vries, G. J. (2014). Slicing up global value chains. The Journal of Economic Perspectives, pages 99-118.

\section{Appendix}
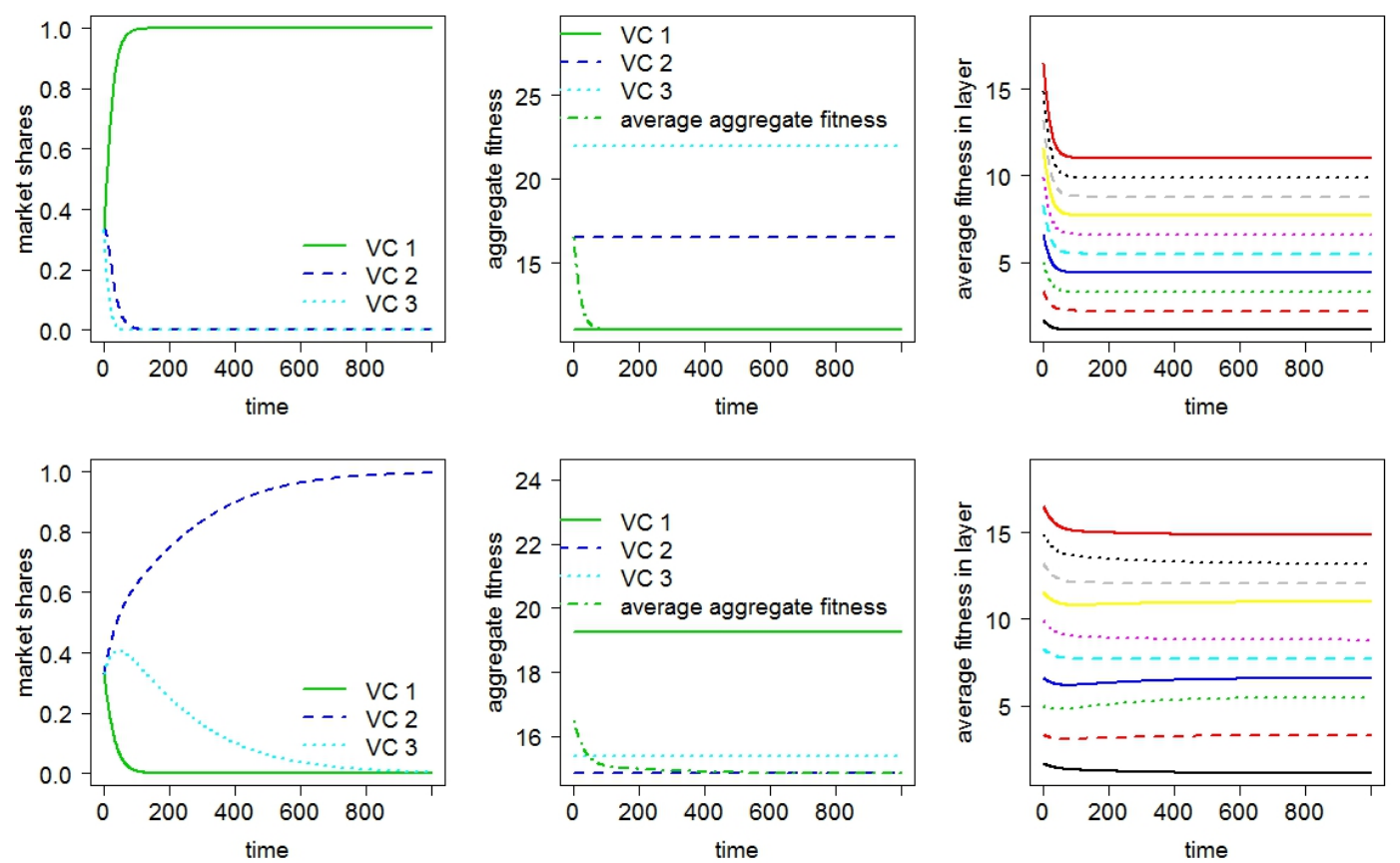

Figure 13: Dynamics with ordered and random matching with ten layers

Note: The upper panel corresponds to ordered matching, while the lower to random matching. $M=10$ and $N=3$. 

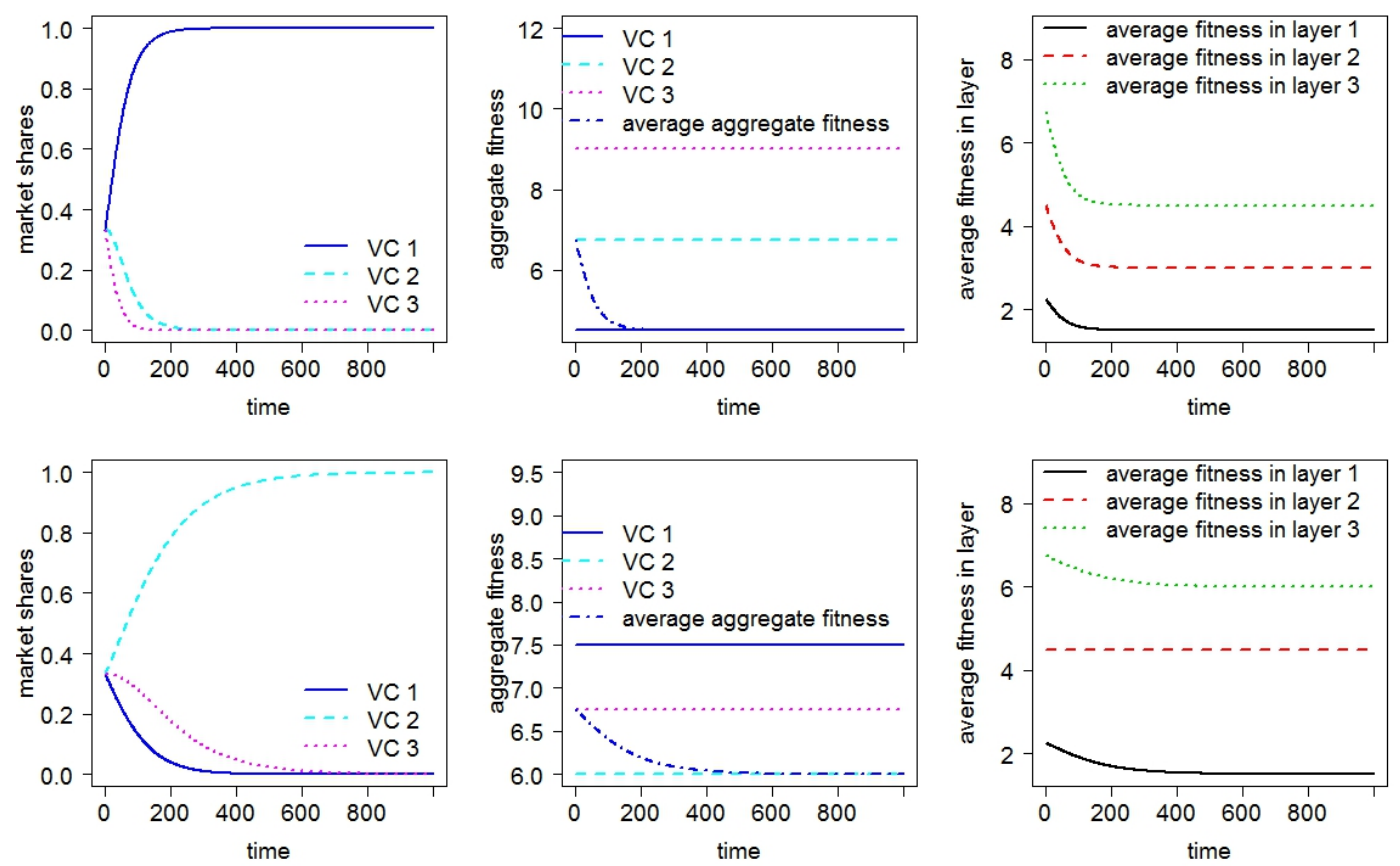

Figure 14: Dynamics with ordered and random matching with alternative profit margin Note: The upper panel corresponds to ordered matching, while the lower to random matching. $M=3, N=3$ and $\phi=0.5$.


Figure 15: Dynamics with ordered and random matching with larger variance in fitness

Note: While in the default case, as it was mentioned earlier, firms' productivity has been drawn in a way that each firm surpasses the next one by 0.5 (which was leading to $\left(\sigma_{c}^{m}\right)^{2} \approx 0.167$ ), here we increase the step to 1 and, respectively, the $\left(\sigma_{c}^{m}\right)^{2}$ to $\approx 0.67$.

The upper panel corresponds to ordered matching, while the lower to random matching. $M=3$ and $N=3$. 

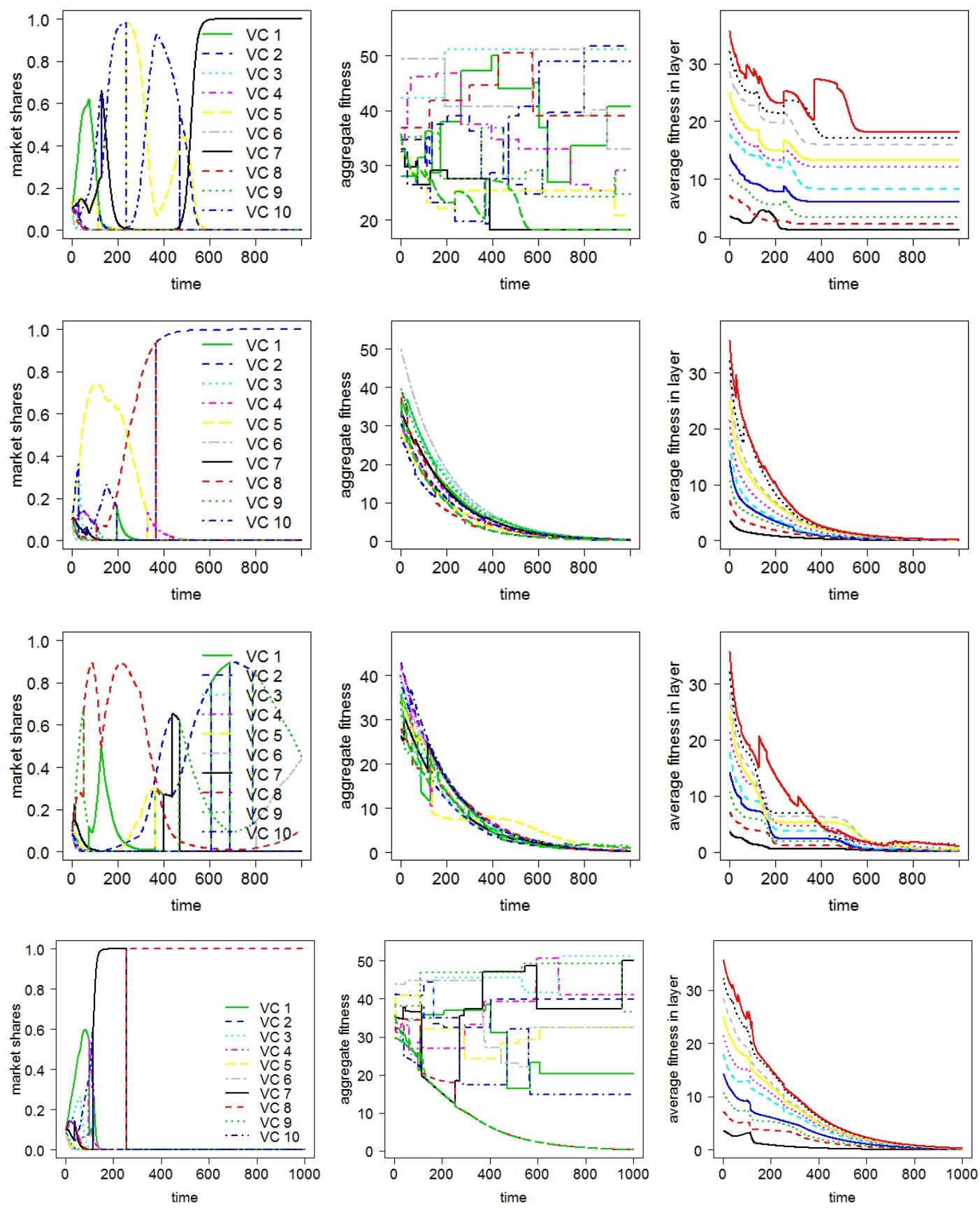

Figure 16: Dynamics with random matching and switching for different innovation scenarios

Note: The upper panel corresponds to no innovation, the next to innovation with CRS, the third from the top to innovation with DRS, and the bottom one- to innovation with IRS. $M=10, N=10$ and $S C=10 \%$. 

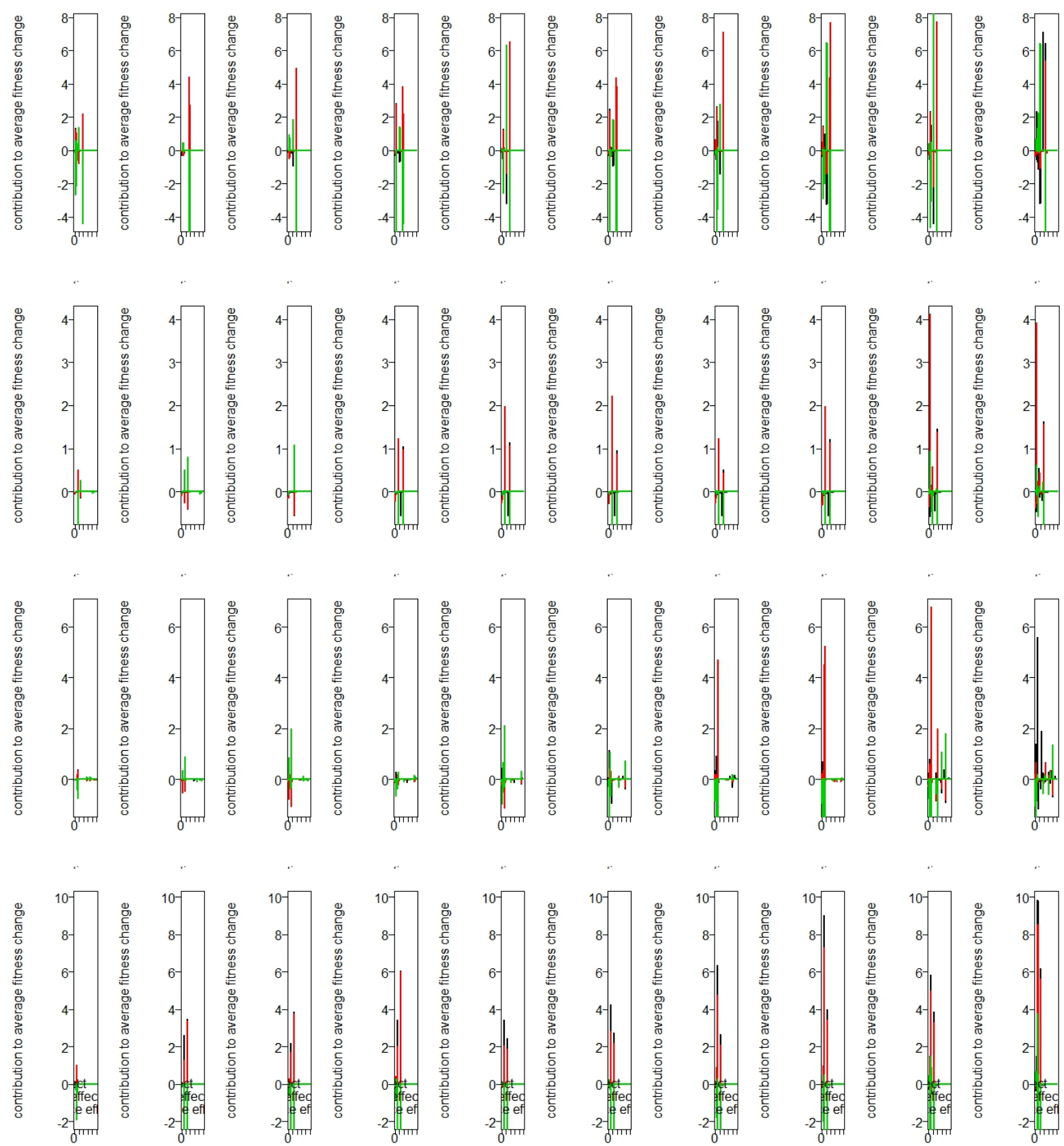

Figure 17: Decomposition of change in average unit cost for different innovation scenarios

Note: The upper panel corresponds to no innovation, the next to innovation with CRS, the third from the top to innovation with DRS, and the bottom one- to innovation with IRS. $M=10, N=10$ and $S C=10 \%$. 


\section{Working Paper Series in Economics}

recent issues

No. 83 Uwe Cantner, Ivan Savin, Simone Vannuccini: Replicator dynamics in value chains: Explaining some puzzles of market selection, February 2016

No. 82 Helena Barnard, Robin Cowan, Moritz Müller: On the value of foreign PhDs in the developing world: Training versus selection effects, January 2016

No. 81 Enno Mammen, Christoph Rothe, Melanie Schienle: Semiparametric estimation with generated covariates, January 2016

No. 80 Carsten Bormann, Julia Schaumburg, Melanie Schienle: Beyond dimension two: A test for higher-order tail risk, January 2016

No. 79 Frank Betz, Nikolaus Hautsch, Tuomas A. Peltonen, Melanie Schienle: Systemic risk spillovers in the European banking and sovereign network, January 2016

No. 78 Armin Falk and Nora Szech: Pleasures of skill and moral conduct, January 2016

No. 77 Kirill Borissov, Mikhail Pakhnin, Clemens Puppe: On discounting and voting in a simple growth model, December 2015

No. 76 Nikolaus Schweizer and Nora Szech: A quantitative version of Myerson regularity, December 2015

No. 75 Tim Deeken: Schumpeterian growth with technological interdependence: An application to US states, November 2015

No. 74 Tim Deeken: Knowledge spillovers: On the impact of genetic distance and data revisions, November 2015

No. 73 Christian Feige and Karl-Martin Ehrhart: Voting and transfer payments in a threshold public goods game, November 2015 